\title{
Bayesian spatio-temporal modelling of tobacco-related cancer mortality in Switzerland
}

\author{
Verena Jürgens ${ }^{1,2}$, Silvia Ess 3 , Harish C. Phuleria ${ }^{1,2}$, Martin Früh ${ }^{4}$, Matthias Schwenkglenks 5 , \\ Harald Frick ${ }^{6}$, Thomas Cerny ${ }^{4}$, Penelope Vounatsou ${ }^{1,2}$ \\ ${ }^{1}$ Department of Epidemiology and Public Health, Swiss Tropical and Public Health Institute, P.O. Box, CH- \\ 4002 Basel, Switzerland; ${ }^{2}$ University of Basel, P.O. Box, CH-4003 Basel, Switzerland; ${ }^{3}$ Cancer Registry of St. \\ Gallen and Appenzell, P.O. Box, CH-9000 St. Gallen, Switzerland; ${ }^{4}$ Department of Medical Oncology- \\ Hematology, Kantonsspital St. Gallen, P.O. Box, CH-4007 St. Gallen, Switzerland; ${ }^{5}$ Institute of Pharmaceutical \\ Medicine, University of Basel, P.O. Box, CH-4031 Basel, Switzerland; ${ }^{6}$ Cancer Registry Grisons and Glarus, \\ Kantonsspital Graubünden, P.O. Box, CH-7000 Chur, Switzerland
}

\begin{abstract}
Tobacco smoking is a main cause of disease in Switzerland; lung cancer being the most common cancer mortality in men and the second most common in women. Although disease-specific mortality is decreasing in men, it is steadily increasing in women. The four language regions in this country might play a role in this context as they are influenced in different ways by the cultural and social behaviour of neighbouring countries. Bayesian hierarchical spatio-temporal, negative binomial models were fitted on subgroup-specific death rates indirectly standardized by national references to explore age- and gender-specific spatio-temporal patterns of mortality due to lung cancer and other tobacco-related cancers in Switzerland for the time period 1969-2002. Differences influenced by linguistic region and life in rural or urban areas were also accounted for. Male lung cancer mortality was found to be rather homogeneous in space, whereas women were confirmed to be more affected in urban regions. Compared to the German-speaking part, female mortality was higher in the French-speaking part of the country, a result contradicting other reports of similar comparisons between France and Germany. The spatio-temporal patterns of mortality were similar for lung cancer and other tobacco-related cancers. The estimated mortality maps can support the planning in health care services and evaluation of a national tobacco control programme. Better understanding of spatial and temporal variation of cancer of the lung and other tobacco-related cancers may help in allocating resources for more effective screening, diagnosis and therapy. The methodology can be applied to similar studies in other settings.
\end{abstract}

Keywords: Bayesian inference, conditional autoregressive models, disease mapping, lung cancer mortality, Markov chain Monte Carlo simulation, tobacco smoking, Switzerland.

\section{Introduction}

In Switzerland, lung cancer is the first cause of cancer mortality in men and the second in women (after breast cancer), accounting for 2,900 deaths per year (Berrut and Junker, 2008). In 1970, the mortality rate per 100,000 inhabitants was around 60 cases for males, whereas it was only five for females but, by 2004, it had decreased to 45 for males and increased to 16 for females (Berrut and Junker, 2008). Also, the geographical distribution of the disease differs remarkably by gender with female lung cancer showing high concentrations in the cities, whereas male lung cancer is

\footnotetext{
Corresponding author:

Penelope Vounatsou

Department of Epidemiology and Public Health

Swiss Tropical and Public Health Institute

P.O. Box, CH-4002 Basel, Switzerland

Tel. +41 61284 8109; Fax +41 612848105

E-mail: penelope.vounatsou@unibas.ch
}

clustered in the central, more rural and industrialised part of the country (Schüler and Bopp, 1997). Tobacco smoking is the main cause (Tyczynski et al., 2003), but can also result in cancers of the larynx, oral cavity, pharynx and oesophagus (IARC, 2004). Even passive exposure to tobacco smoke raises the risk of disease (Subramanian and Govindan, 2007). The Swiss Federal Office of Public Health (FOPH) launched a tobacco prevention programme for the period 2001-2008, later extended to also cover the following years (20092012). The main objective of this programme is to reduce the number of tobacco-related deaths and diseases in Switzerland. To achieve appropriate public health decisions, differences in regions influenced by certain factors, e.g. gender and whether people live in urban or rural neighbourhoods, have to be identified. Maps of the spatial patterns and trends of lung cancer and other tobacco-related cancers can assist the national tobacco programme by identifying high-priority areas for particularly intensive anti-tobacco campaigns. 
Over the last 15 years, Bayesian hierarchical spatiotemporal models have been widely used for disease mapping (Xia et al., 1997; Bell and Broemling, 2000; Johnson, 2004). This methodology enables the estimation of covariate-adjusted smoothed maps highlighting patterns of the disease and exploring covariate effects. In Switzerland, only a few studies exploring the temporal differences and trends in lung cancer mortality have been published (La Vecchia et al., 1988; Levi et al., 2006). Available estimations of geographical disparities are limited to raw rates at the regional level and cover only selected years (Luthi et al., 2005; Bouchardy et al., 2011; NICER, 2011a,b). Mapping the raw rates of the disease mortality can be non-informative and even misleading by overestimating the mortality in small populations (Clayton and Kaldor, 1987).

The aim of this paper was to explore age- and gender-specific spatio-temporal patterns of lung cancer and other tobacco-related cancer mortality rates in Switzerland using Bayesian hierarchical spatio-temporal models. We also wanted to use this approach to determine differences between rural or urban living and, as Switzerland is a multilingual country, extend the investigation into age- and gender-specific mortality by linguistic region.

\section{Materials and methods}

\section{Data sources}

Mortality data were provided by the Federal Statistical Office (FSO). The data covered yearly death records during 1969-2008 at the individual level. Information about year of birth, age at death, sex, municipality of residence, nationality and cause of death was available. During the period covered in this study, there was a transition from the $8^{\text {th }}$ revision of international classification of diseases (ICD-8) to ICD10 in the period 1994/1995. We therefore chose to standardize the whole database according to ICD-10.

Our analysis was separated into two parts. On the one hand we focused exclusively on lung cancer mortality as its smoking-attributable fraction is very high and therefore reflects trends in smoking behaviour. On the other hand, we analysed mortality of all tobacco-related cancers, including lung cancer. Following the definition of Doll and Peto (1976), the following cancers were considered as tobacco-related: lung (C33-C34), oesophagus (C15), rectum (C20), pancreas (C25), bladder (C67) and cancer of other respiratory sites (C00-C14), including cancer of the lip, tongue, mouth, larynx, trachea and pharynx (excluding nasopharynx).
Population size by age, sex and municipality was obtained from the Swiss census. The municipality was identified by name and the given FSO municipality number. During the study period, a census was carried out every 10 years starting in 1970 . Due to the missing population data for the interim years, we divided the study into four periods, each covering the four years closest to the census year, i.e. 1969-1972, 19791982, 1989-1992 and 1999-2002. The population size was assumed to be constant within each period. The four main language regions of Switzerland (German, French, Italian and Romansh; see Fig. 1) were taken into account because the language can be used as proxy for culture and behaviour. Language information at the municipality level was obtained from the FSO.

Digital information on the structure of the municipality boarders of Switzerland in 2009, given by geospatial data in shapefile format, was extracted from the FSO website (FSO, 2012b). Municipalities were considered as rural if the population density was less than 150 people per $\mathrm{km}^{2}$ and otherwise as urban, following the definition of the Organisation for Economic Co-operation and Development (OECD) (Schrader, 1997). Information on the geographical size of each municipality was extracted from the shapefile offered by the FSO. The current number of Swiss municipalities amounts to about 2,700, more than 1,500 of which have less than 1,000 inhabitants. The number of municipalities with population size greater than 10,000 is less than 120 (census of 2000). There have been numerous fusions and partitions of municipalities over the time of the study. The death records of the mortality dataset were updated by the FSO to fit the municipality structure of October 2009. To align the data spatially, we converted the population data of the last four censuses into this municipality structure. Municipalities without population were identified and merged with one of their immediate neighbours. The shapefiles were modified in $\mathrm{R}$ ( $\mathrm{R}$ Development Core Team, 2011) to restructure the municipality boarders.

\section{Statistical analysis}

Spatio-temporal models for all tobacco-related cancer mortality rates were fitted separately for each gender and age group. Age was grouped in two categories: middle aged (35-59 years old) and elderly (60 years old and above) according to Peto et al. (1992). Mortality before age 35 years was excluded. Time trends were modelled as a categorical covariate with 


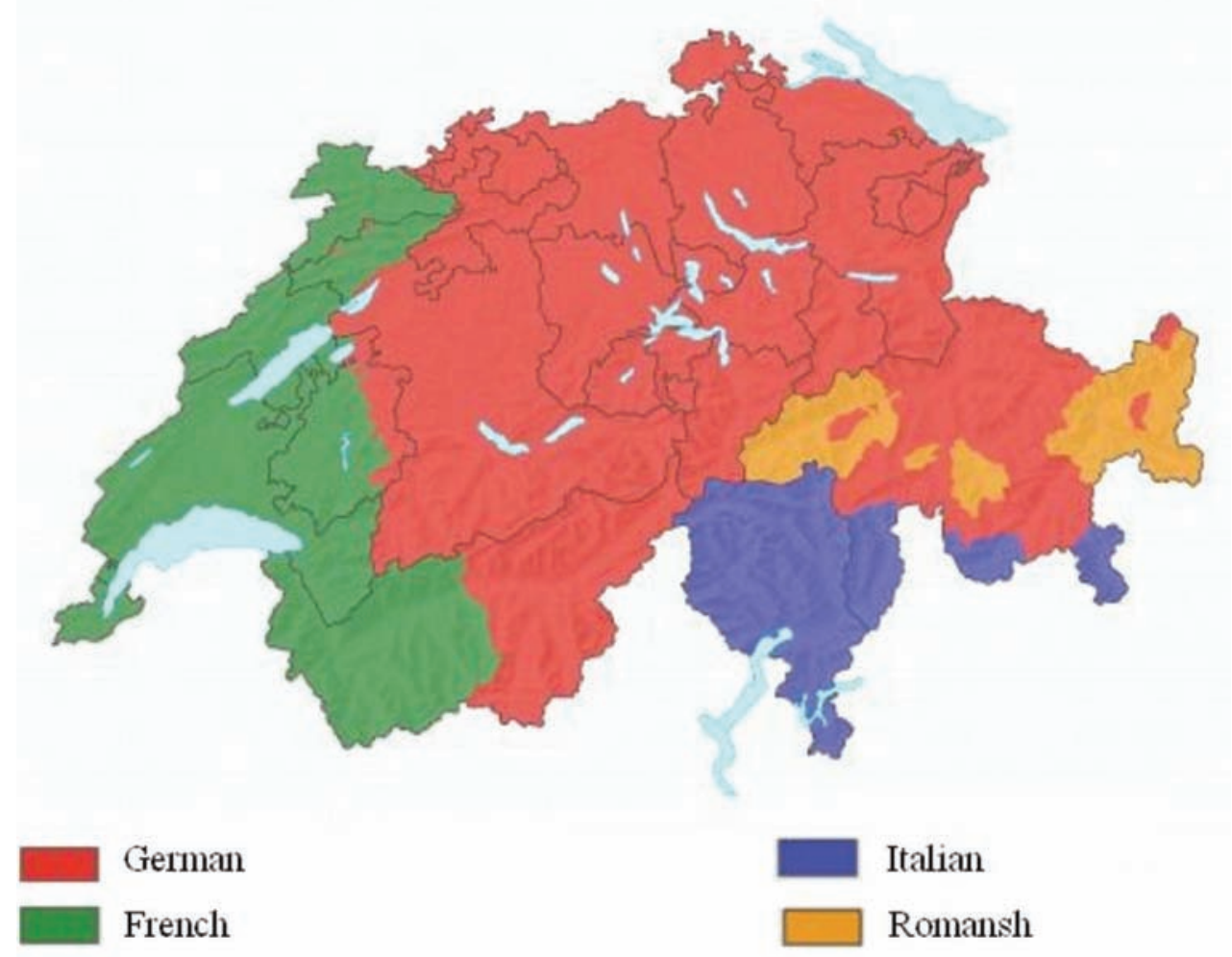

Fig. 1. Language regions of Switzerland in the year 2000 (source: FSO, 2012a).

four levels corresponding to the periods: 1969-1972, 1979-1982, 1989-1992 and 1999-2002.

Multivariate negative binomial regression models were used to (i) assess the patterns of age- and genderspecific lung mortality due to cancer and other tobacco-related cancers in space and time; and (ii) determine differences by language and type of dwelling (urban or rural). Spatial correlation was considered by introducing random effects at the municipality level. Models were formulated following a Bayesian inferential framework, considering age- and gender-specific interactions of time periods with language region and type of dwelling.

Mortality rates are often standardised to compare observed and expected rates with reference to a standard population (Oberaigner and Vittadello, 2010). Standardisation may be direct or indirect (Breslow and Day, 1987), the latter usually done by calculating the standardised mortality ratios (SMRs) (Johnson, 2004). This is recommended if the mortality variation withincountry is of primary interest (Estève et al., 1994; PAHO, 2002). In this case, age- and gender-specific SMRs were used to measure mortality. Standardisation over the entire study population was not appropriate because of large absolute differences in disease occurrence. Therefore, indirect standardisa- tion was done using the subgroup-specific national death rate averaged across the whole study period from 1969 to 2002 . However, this meant that the estimates of the temporal trend for each period had to be interpreted in relation to the remaining periods for the specific age group and gender. Since the resulting subgroup maps cannot be compared directly because of the specific standardisation for each subgroup, a separate analysis was carried out for the subset of mortality data during the 1999-2002 period, standardising only over the corresponding time. To take into account disparities in age distributions among municipalities, all SMRs were additionally standardised by 5-year age groups, starting with age group 35-39 years (Sturtz and Ickstadt, 2007). An SMR of 1.0 implies that there is no difference between the mortality rate of the municipality under consideration and the national rate for the specific subgroup. An SMR that is lower or higher than 1.0 stands for a mortality rate that is lower or higher than the national average.

We assumed the observed age- and gender-specific counts of lung and all tobacco-related cancer deaths $Y_{i j l t}$ in municipality $i(i=1, \ldots, \mathrm{N})$, gender $j(j=1,2)$ and age group $l(l=1,2)$ in period $t$ to follow a negative binomial distribution $Y_{i j l t} \sim \operatorname{NegBin}\left(p_{i j l t}, r\right)$ with parameters $p_{i j l t}$ and $r$, where $p_{i j l t}$ relates to the average 
number of cases via the formula $p_{i j l t}=r /\left(r+\mu_{i j l t}\right)$. Ageand gender-specific spatial random effects as well as possible non-linear trends were modelled on the log of the mean age SMR following model formulations according to Xia et al. (1997):

$$
\log \left(\mu_{i j \mid t}\right)=\log \left(E_{i j \mid t}\right)+\alpha+X_{i s}^{T} \beta_{s}+\phi_{i j l}
$$

where $E_{i j l t}$ is the age- and gender-specific expected number of deaths, $X_{i s}$ the vector of covariates $s$ related to municipality $i$ and $\beta_{s}$ the coefficients of associated covariates. Spatial correlation was introduced by age $(l)$ and gender-specific (j) random effect $\phi_{i j l}$ on municipality level $(i)$, modelled via a CAR process (Besag et al., 1991; Bernardinelli and Montomoli, 1992). Spatial dependency among the municipalities was introduced by the conditional prior distribution of the age- and gender-specific $\phi_{i}$ with

$$
\phi_{i} \mid \phi_{q_{q x i}} \sim \mathcal{N}\left(\frac{\gamma \sum_{\substack{q=1 \\ q \neq i}}^{N} c_{i q} \phi_{q}}{w_{i}}, \frac{\sigma^{2}}{w_{i}}\right)
$$

where $c_{i q}$ indicates the degree of spatial influence of municipality $i$ to the remaining municipalities, taking the value 1 if they are adjacent and otherwise $0, \gamma$ quantifying the overall spatial dependence, assumed to be 1 following Besag et al. (1991), and $w_{i}$ being the number of neighbours of municipality $i$. As the Bayesian formulation requires, specification of prior distributions for the model parameters were specified. The variance parameter $r$, controlling overdispersion, was assumed to follow a gamma prior distribution. We assumed a flat prior for the intercept $\alpha$ and uniform prior distributions $(-\infty, \infty)$ for the regression coefficients $\beta_{s}$.

After a "burn-in" of 1,000 iterations the model was run for another 100,000 iterations achieving convergence, which was assessed by graphical inspection of the Markov chain output. Finally, another 10,000 iterations were run to save a sample of 1,000 with thinning 10 to obtain summaries of the posterior distribution of the parameters.

Preliminary analyses fitting negative binomial models were carried out in Stata/IC (Stata Corporation; College Station, USA). Bayesian models were fitted using OpenBUGS (Imperial College and MRC, London, UK). The resulting maps of all tobacco-related cancer mortality rates and results of the interaction analysis are given as supplementary files (Figs. S1-S6 and Tables S1 and S2). The Kulldorff's spatial scan statistic implemented in the DCluster package within the R software was used to detect significant mortali- ty clusters in the most recent period (Kulldorf and Nagarwalla, 1995; Gómez-Rubio et al., 2005).

\section{Results}

Lung cancer mortality

\section{Males}

Table 1 reports a decline of lung cancer deaths in males between 1990 and 2000. Table 2 shows the results of the spatial negative binomial regression analysis carried out on the mortality data over the whole study period. Lung cancer SMR in younger men (35-59 years old) decreased by $40 \%$ during 1999-2002 in comparison to 1969-1972. This trend is illustrated in Fig. 2. A similar result has not been confirmed for older men ( $\geq 60$ years). On the contrary, SMR increased by around $25 \%$ in the 1980 s and 1990 s and was not significantly different in 1999-2002, compared to the 1970s. Also, results indicate no significant differences in lung cancer mortality between the language regions (Table 2, Figs. 2 and 3).

The SMR was 7\% higher for older men in urban areas. Models including interaction terms (Table S1) indicate that the mortality in younger men had decreased everywhere in Switzerland by the year 2000, with the exception of the Romansh-speaking and urban French-speaking regions. Older males showed an increasing trend in the rural parts but the urban areas showed no difference in SMR except for the German ones, where SMRs decreased between the 1970s and 2000. Fig. 4 illustrates the most recent period (1999-2002) revealing a lower lung cancer mortality in the alpine regions. While the highest mortality rate for young men was concentrated in the rural French-speaking region, high mortality in older men was more common in the generally rural Germanspeaking and Italian-speaking parts.

Table 1. Lung cancer mortality in Switzerland: death counts and proportion of males and females.

\begin{tabular}{lccc}
\hline Year & Rate* & Males & Females \\
\hline 1970 & 68 & $1,568(90 \%)$ & $175(10 \%)$ \\
1980 & 77 & $2,111(87 \%)$ & $311(13 \%)$ \\
1990 & 76 & $2,245(82 \%)$ & $491(18 \%)$ \\
2000 & 69 & $2,044(72 \%)$ & $781(28 \%)$ \\
\hline
\end{tabular}

*Per 100,000 inhabitants. 
Table 2. Spatio-temporal model estimates of age- and gender-specific lung cancer mortality in Switzerland from 1969-1972 to 1999-2002.

\begin{tabular}{|c|c|c|c|c|}
\hline \multirow{3}{*}{ Age group (years) } & \multicolumn{2}{|c|}{ Males } & \multicolumn{2}{|c|}{ Females } \\
\hline & $35-59$ & $\geq 60$ & $35-59$ & $\geq 60$ \\
\hline & \multicolumn{4}{|c|}{ SMR ratio $\left(95 \% \mathrm{BCI}^{*}\right)$} \\
\hline \multicolumn{5}{|l|}{ Period } \\
\hline $1969-1972$ & 1.00 & 1.00 & 1.00 & 1.00 \\
\hline 1979-1982 & $1.07(1.00 ; 1.15)$ & $1.26(1.20 ; 1.31)$ & $1.64(1.31 ; 2.05)$ & $1.32(1.16 ; 1.50)$ \\
\hline 1989-1992 & $0.81(0.75 ; 0.88)$ & $1.23(1.18 ; 1.29)$ & $2.48(2.03 ; 3.04)$ & $1.78(1.58 ; 2.01)$ \\
\hline 1999-2002 & $0.60(0.55 ; 0.64)$ & $0.96(0.92 ; 1.01)$ & $3.50(2.87 ; 4.28)$ & $2.52(2.25 ; 2.86)$ \\
\hline \multicolumn{5}{|l|}{ Language } \\
\hline German & 1.00 & 1.00 & 1.00 & 1.00 \\
\hline French & $1.16(0.99 ; 1.35)$ & $1.07(0.94 ; 1.17)$ & $1.36(0.98 ; 1.74)$ & $1.30(1.07 ; 1.59)$ \\
\hline Italian & $1.25(0.93 ; 1.66)$ & $1.15(0.82 ; 1.41)$ & $0.93(0.58 ; 1.39)$ & $1.23(0.71 ; 2.06)$ \\
\hline Romansh & $0.95(0.58 ; 1.44)$ & $0.94(0.71 ; 1.25)$ & $0.76(0.23 ; 1.87)$ & $0.54(0.25 ; 1.01)$ \\
\hline \multicolumn{5}{|l|}{ Dwelling } \\
\hline Rural & 1.00 & 1.00 & 1.00 & 1.00 \\
\hline Urban & $0.97(0.91 ; 1.03)$ & $1.07(1.03 ; 1.12)$ & $1.20(1.04 ; 1.36)$ & $1.28(1.18 ; 1.40)$ \\
\hline Spatial variation & $0.31(0.26 ; 0.37)$ & $0.31(0.27 ; 0.35)$ & $0.39(0.28 ; 0.49)$ & $0.35(0.29 ; 0.42)$ \\
\hline
\end{tabular}

"Bayesian credible interval.
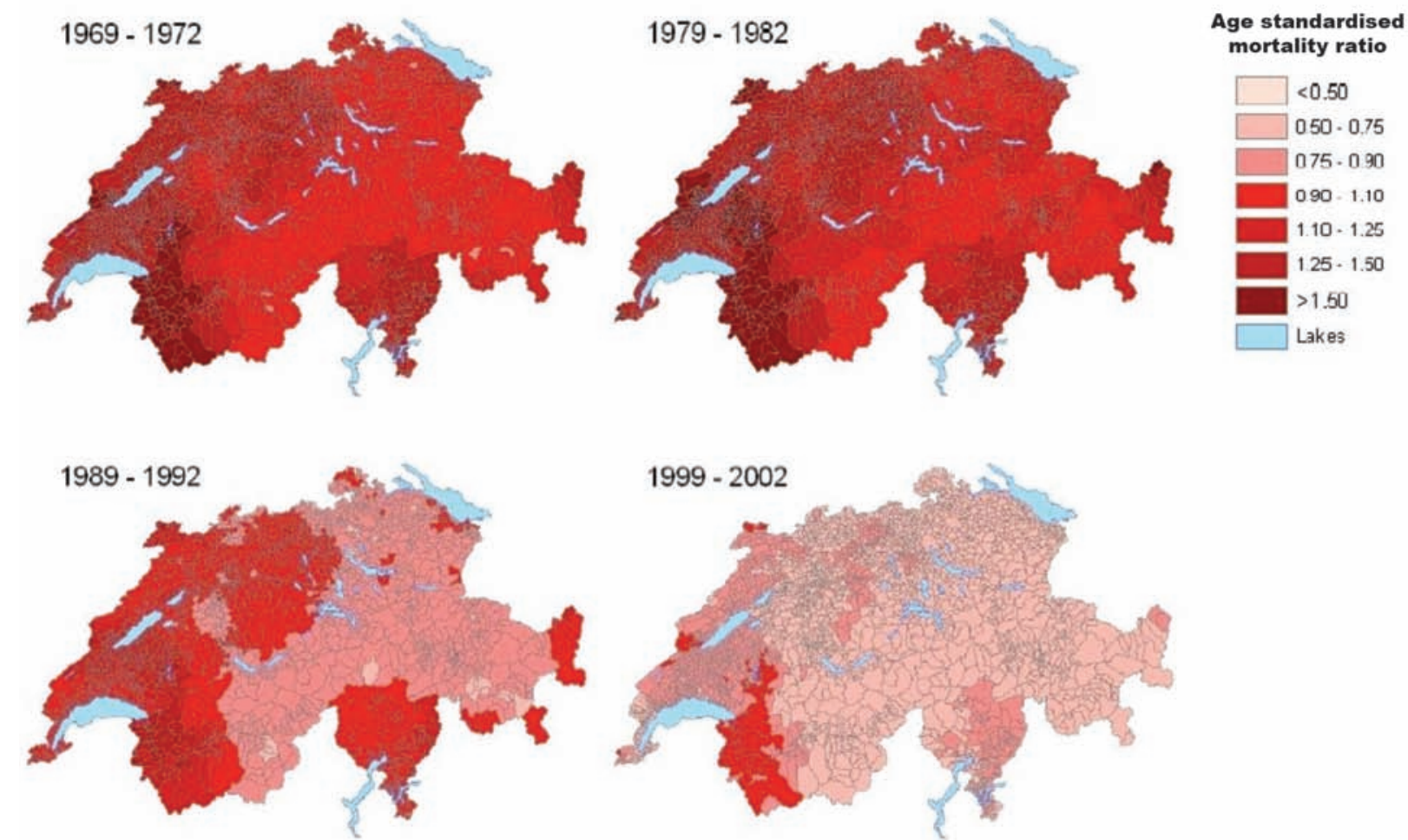

Fig. 2. Geographical distribution of lung cancer mortality risks from 1969-1972 to 1999-2002 in Switzerland for males aged 35-59 years. 

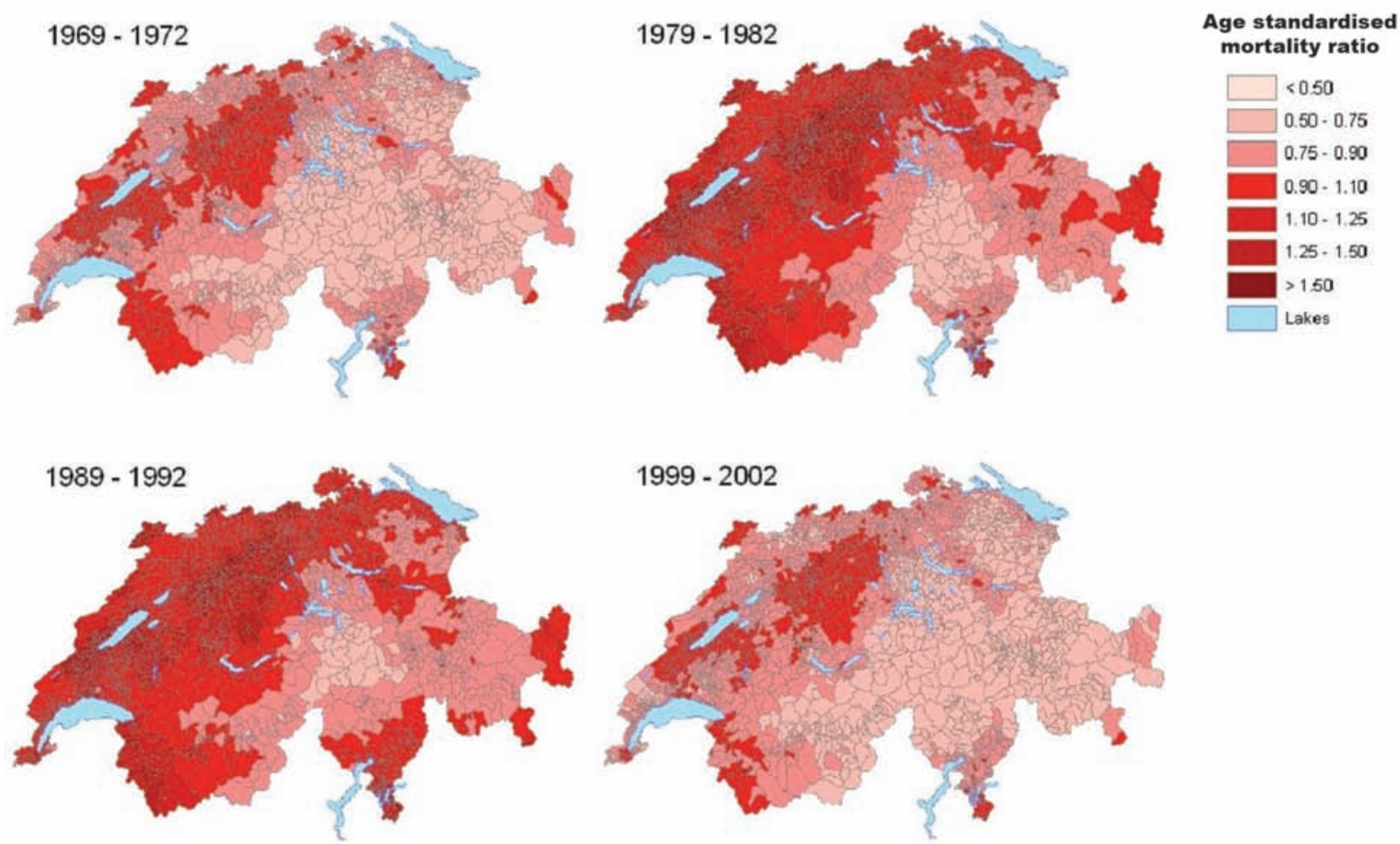

Fig. 3. Geographical distribution of lung cancer mortality risks from 1969-1972 to 1999-2002 in Switzerland for males aged 60 years and above.

(a) Male, age $35-59$ years

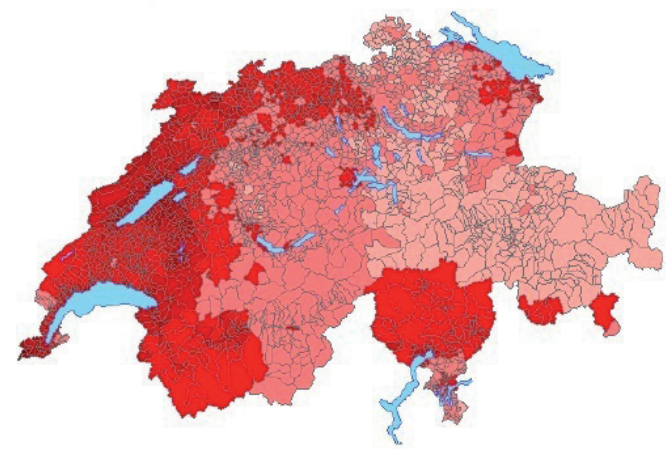

(c) Female, age 35-59 years

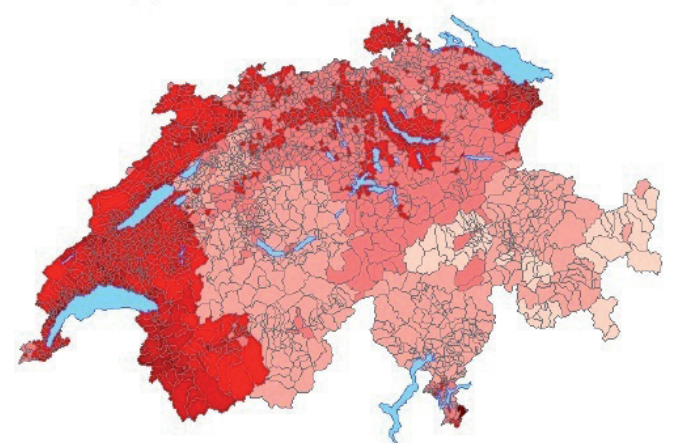

(b) Male, age $\geq 60$ years

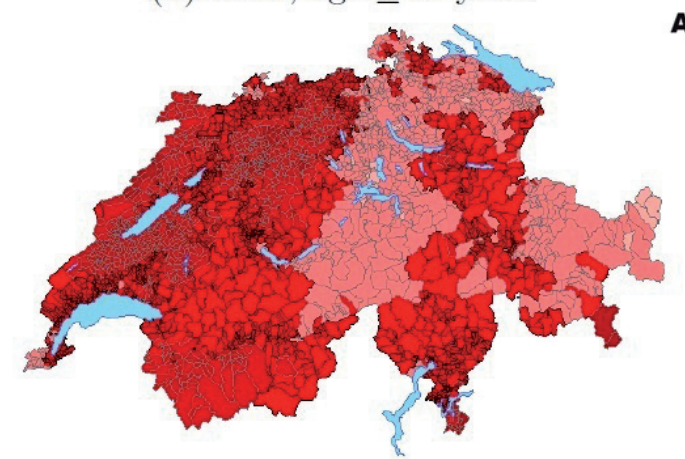

Age standardised

mortality ratio

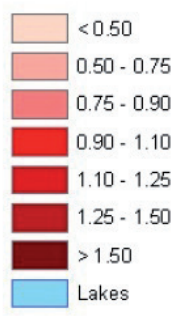

Fig. 4. Geographical distribution of age- and gender-specific lung cancer mortality risks in Switzerland in the period 1999 2002.

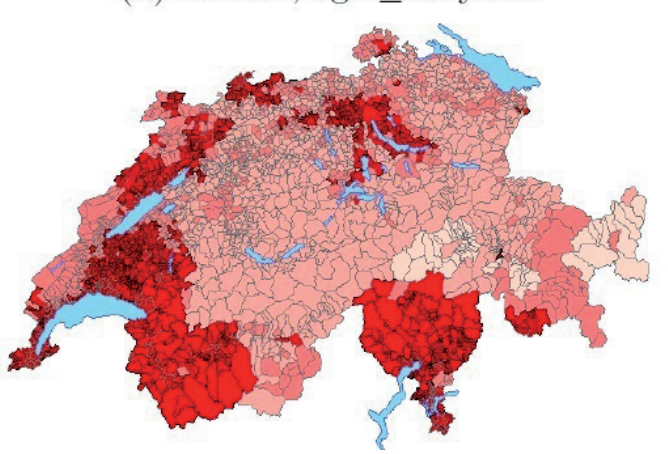




\section{Females}

Raw data (Table 1) indicate that female mortality increased between 1970 and 2000. Also, Bayesian spatial models suggest an increasing trend during the last 30 years. In particular, the SMR of younger females was 3.5 times higher in 2000 than in the 1970s. The SMR for older women was 2.5 times higher in 1999. 2002 compared to 1969-1972 (Table 2). The SMR in urban regions was more than $20 \%$ higher than in the rural areas (Figs. 5 and 6). In the French-speaking part, older females had significantly higher mortality compared to the German one (SMR ratio of 1.30). The lowest mortality was estimated in the Romansh part although the difference seen is not statistically significant, probably due to the small number of deaths $(0.13 \%$ out of the total number for females in the year 2000). While the SMR increased from the 1970s to 2000 in all remaining regions, it was not significantly different in 2000 in the rural Italian region. However, this result was not seen in older women. Lung cancer mortality increased in the French-speaking and urban German-speaking regions for the older age group during the 1990s and in the remainder of regions during 2000. Fig. 4 shows higher mortality in the Frenchspeaking area in 2000, whereas younger females
Table 3. Tobacco-related cancer mortality in Switzerland: death counts and proportion of males and females.

\begin{tabular}{cccc}
\hline Year & Rate* & Males & \multicolumn{1}{c}{ Females } \\
\hline 1970 & 130 & $2,947(79 \%)$ & $790(21 \%)$ \\
1980 & 152 & $3,747(78 \%)$ & $1,050(22 \%)$ \\
1990 & 150 & $3,924(73 \%)$ & $1,440(27 \%)$ \\
2000 & 130 & $3,571(67 \%)$ & $1,781(33 \%)$ \\
\hline
\end{tabular}

*Per 100,000 inhabitants.

showed the highest mortality in the rural part of this region.

Figs. 2 and 3, Figs. 5 and 6 and Figs. S1-S4 show the spatial pattern of lung and all tobacco-related cancer mortality separately for each age and gender group over the four time periods investigated. The maps presented in Fig. 4 and Fig. S5 show the distribution of lung cancer and all tobacco-related cancer mortality for each subgroup in 1999-2002. The estimates have to be interpreted independently for each subgroup. Fig. 7 and Fig. S6 show the most (red) to the least (yellow) significant clusters of modelled lung and all tobacco-related cancer mortality in 1999-2002 detected by Kulldorff's spatial scan statistic.
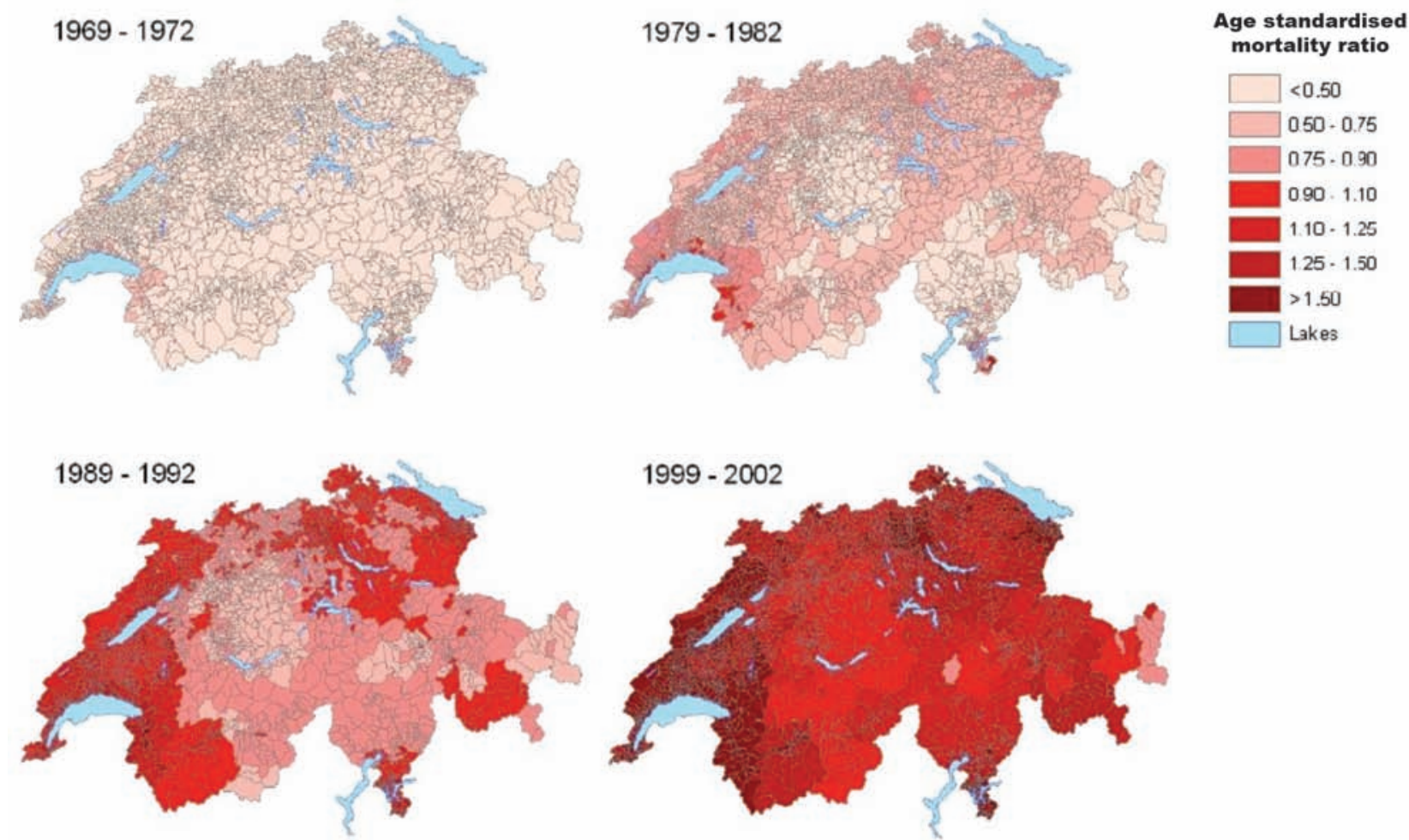

Fig. 5. Geographical distribution of lung cancer mortality risks from 1969-1972 to 1999-2002 in Switzerland for females aged 3559 years. 

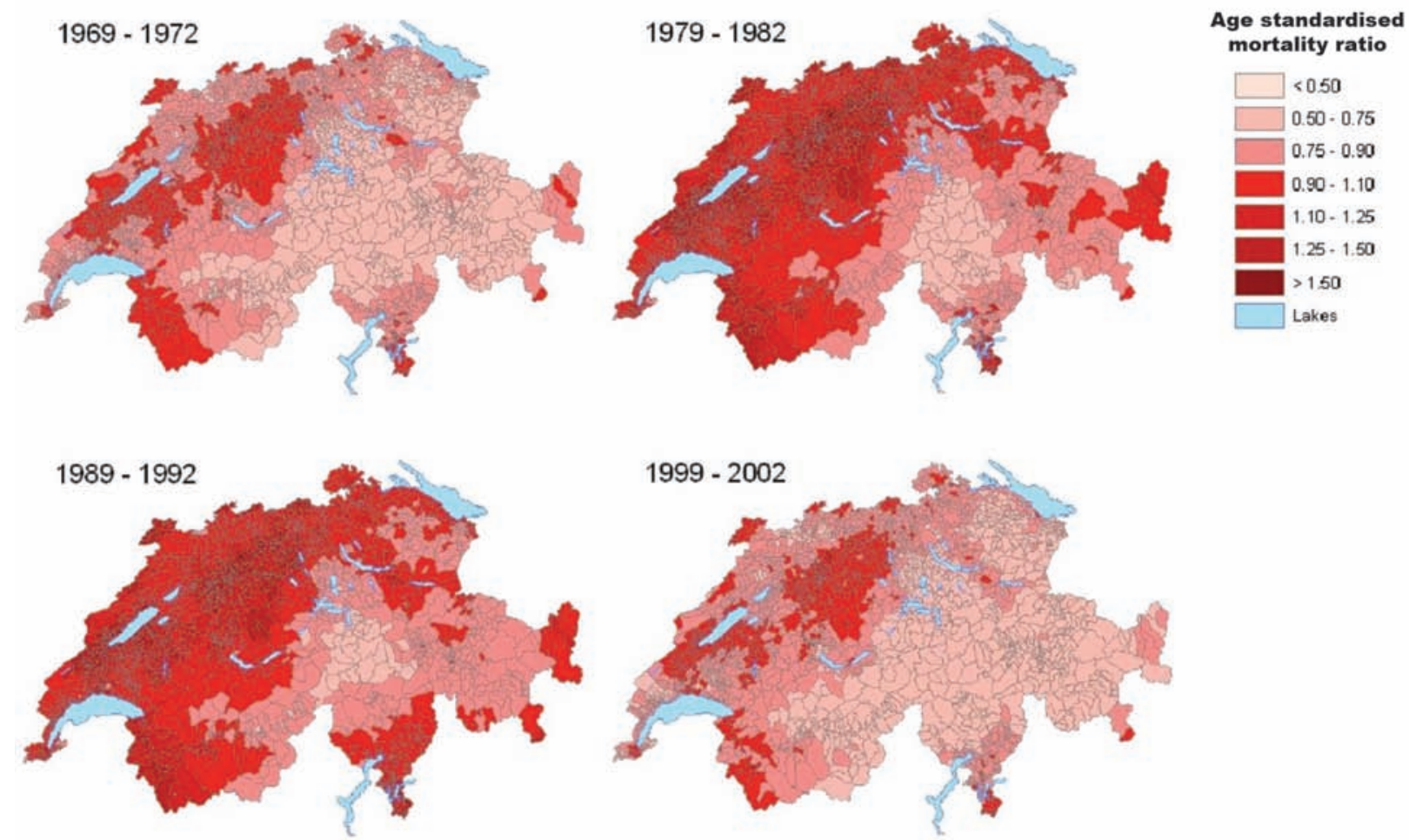

Fig. 6. Geographical distribution of lung cancer mortality risks from 1969-1972 to 1999-2002 in Switzerland for females aged 60 years and above.

\section{Tobacco-related cancer mortality}

Males

The estimates of the Bayesian spatial models regarding all tobacco-related cancer mortality (including lung cancer) indicate a decrease of 33\% for those 3559 years old and $20 \%$ for those aged 60 years and above. For younger males a $21 \%$ significantly higher SMR was observed for the French-speaking region in comparison to the baseline German (Table 4 and Fig. S1). The SMR in older men did not differ between the language regions. Models including interaction terms showed an overall decrease for younger men in 2000 with exception of the urban French part. For the older age group an overall decrease was estimated, except for the rural, French-speaking and Italian-speaking areas.

\section{Females}

Mortality increased steadily over the last 30 years. The SMR nearly doubled for the 35-59 age group and increased by $15 \%$ for the older women from 1969 1972 to $1999-2002$. There were no significant differ- ences between the language regions over the entire study period (Table 4). In comparison to the rural areas, mortality in the urban regions was significantly higher both for younger and older women, $14 \%$ and $11 \%$, respectively (Figs. S3 and S4). In the 1990s, the group aged 35-59 years showed a significantly higher mortality in the German-speaking and rural Frenchspeaking areas. In 1999-2002 an overall increase was observed, except in the rural Italian-speaking areas. In the older age group, there was no significant interaction between time period and language or urban groups observed.

\section{Discussion}

This study explores the spatio-temporal patterns of lung and tobacco-related cancer mortality in Switzerland, for the first time based on advanced Bayesian CAR models. Subgroups defined by age and gender were studied separately. The results show the steep and constant rise, especially in urban regions, of mortality in women due to lung cancer and other tobacco-related cancers. The lung cancer mortality in women was found to be highest in the French-speaking parts of the country, while the language region was 
Table 4. Spatio-temporal model estimates of age- and gender-specific tobacco-related cancer mortality in Switzerland from 19691972 to $1999-2002$.

\begin{tabular}{|c|c|c|c|c|}
\hline \multirow{3}{*}{ Age group (years) } & \multicolumn{2}{|c|}{ Males } & \multicolumn{2}{|c|}{ Females } \\
\hline & $35-59$ & $\geq 60$ & $35-59$ & $\geq 60$ \\
\hline & \multicolumn{4}{|c|}{ SMR ratio $\left(95 \% \mathrm{BCI}^{*}\right)$} \\
\hline \multicolumn{5}{|l|}{ Period } \\
\hline $1969-1972$ & 1.00 & 1.00 & 1.00 & 1.00 \\
\hline 1979-1982 & $1.08(1.01 ; 1.14)$ & $1.10(1.06 ; 1.13)$ & $1.26(1.12 ; 1.42)$ & $1.07(1.00 ; 1.13)$ \\
\hline 1989-1992 & $0.89(0.84 ; 0.95)$ & $1.05(1.01 ; 1.08)$ & $1.57(1.39 ; 1.76)$ & $1.12(1.06 ; 1.19)$ \\
\hline 1999-2002 & $0.67(0.63 ; 0.71)$ & $0.80(0.77 ; 0.83)$ & $1.95(1.74 ; 2.19)$ & $1.15(1.09 ; 1.22)$ \\
\hline \multicolumn{5}{|l|}{ Language } \\
\hline German & 1.00 & 1.00 & 1.00 & 1.00 \\
\hline French & $1.21(1.03 ; 1.43)$ & $1.12(0.96 ; 1.23)$ & $1.14(0.95 ; 1.36)$ & $1.04(0.95 ; 1.20)$ \\
\hline Italian & $1.23(0.87 ; 1.60)$ & $1.12(0.96 ; 1.43)$ & $1.25(0.92 ; 1.73)$ & $1.10(0.76 ; 1.51)$ \\
\hline Romansh & $0.86(0.55 ; 1.20)$ & $0.87(0.72 ; 1.06)$ & $1.15(0.58 ; 2.11)$ & $1.10(0.79 ; 1.46)$ \\
\hline \multicolumn{5}{|l|}{ Dwelling } \\
\hline Rural & 1.00 & 1.00 & 1.00 & 1.00 \\
\hline Urban & $0.97(0.92 ; 1.02)$ & $1.04(1.01 ; 1.07)$ & $1.14(1.04 ; 1.25)$ & $1.11(1.05 ; 1.16)$ \\
\hline Spatial variation & $0.30(0.92 ; 0.36)$ & $0.25(0.22 ; 0.28)$ & $0.32(0.27 ; 0.40)$ & $0.26(0.23 ; 0.32)$ \\
\hline
\end{tabular}

"Bayesian credible interval.

(a) Male, age 35-59 years

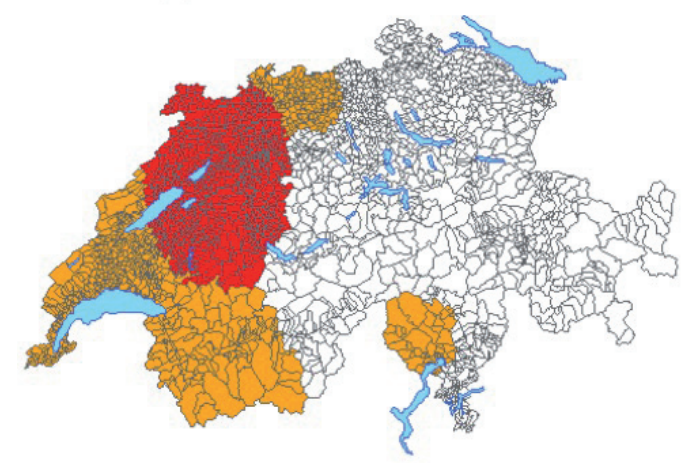

(c) Female, age 35-59 years

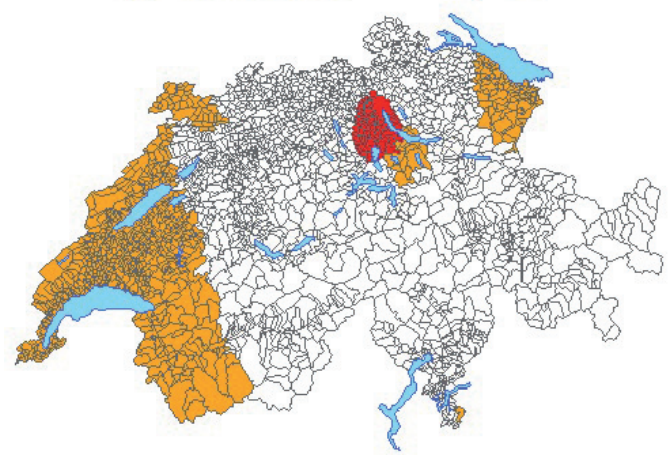

(b) Male, age $\geq 60$ years

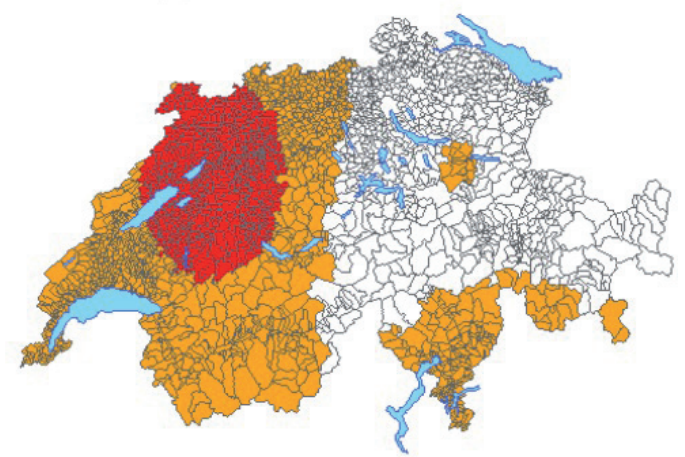

(d) Female, age $\geq 60$ years

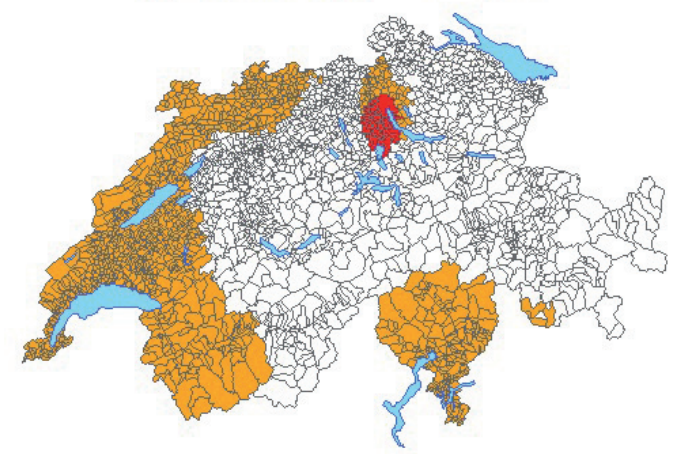

Fig. 7. Clusters of age- and gender-specific lung cancer mortality risks in Switzerland in the period 1999-2002* (*according to Kulldorff's statistic; red colour = highly significant clustering; yellow colour = significant clustering at a lower level). 
not significantly associated with lung cancer mortality in men. The rates of male lung cancer, and all tobacco-related cancer mortality, were higher than those for women but with a decreasing temporal trend. A peak of tobacco-related mortality for males was observed in the 1980s followed by a constant decrease as also seen in other European countries (Levi et al., 2004). Results for lung cancer, and all other forms of tobacco-related cancer mortality, were similar but the temporal trend was particularly striking for lung cancer mortality. In general, around $85 \%$ of the lung cancer cases in Switzerland are attributed to the consumption of tobacco (FOPH, 2012a). The temporal trends observed in lung cancer mortality can be explained by gender-specific changes in smoking habits. These facts and the patterns observed reflect how ubiquitous the habit of smoking is.

Several recent reviews of lung cancer in people who never smoked have highlighted the importance of other risk factors such as genetic predisposition and various forms of exposure, e.g. environmental tobacco smoke, outdoor air pollution, ionizing radiation as well as occupational exposures to carcinogens (Samet et al., 2009; Torok et al., 2011; Couraud et al., 2012). The second most important cause of lung cancer in Switzerland (but far behind that of tobacco) is exposure to radon, especially in alpine regions and in the Jura. Radon is believed to be responsible for 200 lung cancer deaths per year (FOPH, 2012b). Due to a strong combined effect of smoking and radon, most of the radon-induced lung cancers occur among smokers, but radon is the primary cause of lung cancer among people who never smoked (Zeeb and Schannoun, 2009). Radon exposure is assumed to be stable in time, while the temporal and gender-specific trends observed change and are not related to radon exposure.

Schopper and Obrist (2005) report that the highest incidence of male lung cancer is found in western and southern Switzerland, corroborating our findings. Like our results indicate, these authors also found the highest female lung cancer incidence in the western, French-speaking part. Apart from this, Schüler and Bopp (1997) described a cluster of lung cancer in the central part of the German-speaking part of Switzerland, which is a rural but still a highly industrialised region. Socio-economic or environmental factors related to high industrialisation might explain this cluster (Fano et al., 2004), which is confirmed by our analysis for older males (Fig. 3).

High female mortality in the urban areas is likely to be due to the change in female smoking behaviour of the middle of the twentieth century that took place earlier and was more pronounced in the cities (Curtin et al., 1997). Similar trends have been observed in other populations of the Western World (Graham, 1996). Exposure to environmental risks such as air pollution and peer-to-peer tobacco smoke, especially in urban areas may have accentuated the trend (Subramanian and Govindan et al., 2007). A similar observation has been reported in Germany, where lung cancer mortality rates in women doubled from 1960 to 1996 and increased by $155 \%$ in the $45-54$ years age group (Lienert et al., 2000).

Faeh et al. (2009) describe differences in cause-specific mortality between Swiss regions maintaining that patterns follow disparities among European populations suggesting an important, cultural factor. Others beg to differ, e.g. Tyczynski et al. (2003) who compared lung cancer mortality among European countries and report that female lung cancer mortality rates are highest in northern Europe, followed by the western part of the continent. Interestingly, while they found lung cancer mortality in women to be lower in France compared to Germany, we found the Frenchspeaking parts of Switzerland having higher mortality rates than the German-speaking regions, similar to the results of Faeh et al. (2009).

Lopez et al. (1994) describe a model of smoking epidemic defined by different stages. The most crucial component of this model is the lag of three to four decades between the rise in smoking prevalence and the increase in smoking-attributable mortality. According to them, female smoking highest prevalence typically lags males by 10-20 years. In males, lung cancer mortality has declined since the 1980 s, so that if the predictions of Lopez et al. would take place in Switzerland, a reduction in female smoking-related mortality can be expected to start soon. Indeed, a recent decline of female lung cancer incidence and mortality from 2003-2007 has been reported from the USA (Kohler et al., 2011). This trend is expected to continue for at least two more decades. Unfortunately, there is a dearth of data on smoking behaviour in Switzerland for the past few decades. One of the first national surveys was not until 1997. Since then a decrease in the number of smokers for both genders has been reported (Marques-Vidal et al., 2011).

What sets this study apart is the methodological approach using Bayesian CAR models on a small spatial unit (the municipality), allowing the identification of areas with high incidence of lung cancer and other tobacco-related cancer mortality. We updated the boundaries, in many places changed dur- 
ing the 40-year period covered, and defined the urbanization level and language on the basis of the most recent structure, i.e. that of October 2009. This may have wrongly classified those that had been restructured. However, less than $1 \%$ of the municipalities underwent re-classification and this low percentage should not affect the general results of the study. Furthermore, the Bayesian approach introducing spatial correlation at the municipality level should have reduced the impact of any potential reclassification.

Several approaches for disease mapping exist, e.g. count regression models accounting for spatial correlation by the CAR process are widely used. Besag et al. (1991) proposed the inclusion of unstructured random effects into the model to account for heterogeneity in the data. Identifiability issues may arise when there is no prior information about the contribution of the spatial and non-spatial variation to the total one (Eberly and Carlin, 2000). Frequently Poisson regression models are used to map mortality rates but they are based on the assumption of the equality of mean and variance, which is not always valid. Negative binomial models account for unobserved variation by including an additional parameter. We did not consider an unstructured random effect, as we assume that additional variation is captured by the variance parameter of the negative binomial distribution.

Before the change of coding system from ICD-8 to ICD-10 in 1995, a priority rule was used by which cancer was rated high-priority and assigned as cause of death when multiple causes were documented on the death certificate. Especially in older people with several morbidities, this priority rule may have led to inflated cancer rates. However, because the rule was applied centrally and to all death certificates similarly, it cannot have affected the spatial patterns. Moreover it is unlikely that this rule could have had much influence on mortality of persons aged 60 years and above. A re-analysis taking into account the correction factor of 0.96 for lung cancer (Berrut and Junker, 2008) that was provided by the FSO did not change the results of the lung cancer related mortality.

A limitation of the present study is the lack of more recent trends, which is due to the missing population data at the municipality level for the more recent years. As soon as data are available we will carry out further analyses to explore the trends for the years after 2002 and to address potential declining trends in female tobacco-related cancer mortality as seen in the USA. We are currently developing models to estimate inter-censual population data to make use of the full mortality dataset. However, in this study we aggregated the years around censuses, excluding the inter-censual years. Although proportional mortality rate estimates do not rely on population size (Sitas et al., 1989), we compared the results of this study using both standardised and proportional mortality rates. The conclusions by both approaches were similar, suggesting that ignoring inter-censual years does not bias the results. The results also suggest a cohort effect for both genders, which is known for lung cancer mortality (Lee et al., 1990). Most of these findings can be explained by the gender-specific tobacco epidemics. Including information about the birth cohorts in this analysis might improve the estimation of the temporal trends.

Our results and newer trends would be useful as basis for projections and estimates of lung and all tobacco-related cancer mortality in the future. The insights of spatial differences in mortality as well as visualization of time and regional differences in tobacco-related cancer derived from this study will hopefully give new impetus to tobacco control activities and help evaluate the effectiveness of the national control programme.

\section{Acknowledgements}

This work was supported by Oncosuisse [grant number KLS02393-02-2009]. We would like to thank the Swiss Federal Statistical Office for providing the data.

\section{References}

Bell BS, Broemling LD, 2000. A Bayesian analysis for spatial processes with application to disease mapping. Stat Med 19, 957-974.

Bernardinelli L, Montomoli C, 1992. Empirical Bayes versus fully Bayesian analysis of geographical variation in disease risk. Stat Med 11, 983-1007.

Berrut S, Junker C, 2008. Von Generation zu Generation: Entwicklung der Todesursachen 1970 bis 2004. Neuchâtel: Bundesamt für Statistik (BFS).

Besag J, York J, Mollié A, 1991. Bayesian image restoration, with two applications in spatial statistics. Ann I Stat Math 43, 1-20.

Bouchardy C, Lutz JM, Kühni C, 2011. Krebs in der Schweiz Stand und Entwicklung von 1983 bis 2007. Neuchâtel: Bundesamt für Statistik, National Institute for Cancer Epidemiology and Registration (NICER).

Breslow N, Day N, 1987. Statistical methods in cancer research. Volume 2: the design and analysis of cohort studies. Lyon: International Agency for Research on Cancer. 
Clayton DG, Kaldor J, 1987. Empirical Bayes estimates of agestandardized relative risks for use in disease mapping. Biometrics 43, 671-681.

Couraud S, Zalcman G, Milleron B, Morin F, Souquet P, 2012. Lung cancer in never smokers - a review. Eur J Cancer 48, 1299-1311.

Curtin F, Morabia A, Bernstein M, 1997. Smoking behavior in a Swiss urban population: the role of gender and education. Prev Med 26, 658-663.

Doll R, Peto R, 1976 Mortality in relation to smoking: 20 years observations on male British doctors. Brit Med J 2, 1525 1536.

Eberly LE, Carlin BP, 2000. Identifiability and convergence issues for Markov chain Monte Carlo fitting of spatial models. Stat Med 19, 2279-2294.

Estève J, Benhamou E, Raymond L, 1994. Statistical methods in cancer research. Volume IV. Descriptive epidemiology. IARC Scientific Publications.

Faeh D, Minder C, Gutzwiller F, Bopp M, 2009. Culture, risk factors and mortality: can Switzerland add missing pieces to European puzzle? J Epidemiol Commun Health 63, 639-645.

Fano V, Michelozzi P, Ancona C, Capon A, Forastiere F, Perucci CA, 2004. Occupational and environmental exposures and lung cancer in an industrialised area in Italy. Occup Environ Med 61, 757-763.

Federal Office of Public Health (FOPH), 2012a. Rauchen verursacht tödlichen Lungenkrebs. http://www.bag.admin.ch/themen/drogen/00041/00612/03652/03659/index.html?lang=de (accessed: 29 May 2012).

Federal Office of Public Health (FOPH), 2012b. Radon. http://www.bag.admin.ch/themen/strahlung/00046/index.html ?lang=de (accessed: 29 May 2012).

Federal Statistical Office (FSO), 2012a. Sprachgebiete der Schweiz 2000. http://www.bfs.admin.ch/bfs/portal/de/index/themen/01/ 05/blank/key/sprachen.html (accessed: 29 May 2012).

Federal Statistical Office (FSO), 2012b. Generalisierte Gemeindegrenzen 2011. http://www.bfs.admin.ch/bfs/portal/ de/index/dienstleistungen/geostat/datenbeschreibung/generalisiertegemeindegrenzen.html (accessed: 29 May 2012).

Gómez-Rubio V, Ferrándiz-Ferragud J, López-Quílez A, 2005. Detecting clusters of disease with R. J Geogr Syst 7, 189-206. Graham H, 1996. Smoking prevalence among women in the European Community 1950-1990. Soc Sci Med 43, 243-254. IARC, 2004. Tobacco smoke and involuntary smoking. Lyon: IARC Monographs on the Evaluation of Carcinogenic Risks to Humans, Volume 83.

Johnson GD, 2004. Small area mapping of prostate cancer incidence in New York State (USA) using fully Bayesian hierarchical modelling. Int J Health Geogr 3, 29.

Kohler BA, Ward E, McCarthy BJ, Schymura MJ, Ries LA, Eheman C, Jemal A, Anderson RN, Ajani UA, Edwards BK, 2011: Annual Report to the Nation on the Status of Cancer,
1975-2007, Featuring Tumors of the Brain and Other Nervous System. J Natl Cancer I 103, 714-736.

Kulldorff M, Nagarwalla N, 1995. Spatial Disease Clusters: Detection and Inference. Stat Med 14, 799-810.

La Vecchia C, Levi F, Decarli A, Wietlisbach V, Negri E, Gutzwiller F, 1988. Trends in smoking and lung cancer mortality in Switzerland. Prev Med 17, 712-724.

Lee PN, Fry JS, Forey BA, 1990. Trends in lung cancer, chronic obstructive lung disease, and emphysema death rates for England and Wales 1941-1985 and their relation to trends in cigarette smoking. Thorax 45, 657-665.

Levi F, Lucchini F, La Vecchia C, 2006. Trends in cancer mortality in Switzerland, 1980-2001. Eur J Cancer Prev 15, 1-9.

Levi F, Lucchini F, Negri E, La Vecchia C, 2004. Trends in mortality from major cancers in the European Union, including acceding countries, in 2004. Cancer 101, 2843-2850.

Lienert T, Serke M, Schönfeld N, Loddenkemper R, 2000. Lung cancer in young females. Eur Respir J 16, 986-990.

Lopez AD, Collishaw NE, Piha T, 1994. A descriptive model of the cigarette epidemic in developed countries. Tob Control 3, 242-247.

Luthi JC, Clere-Berod A, Favre F, de Weck D, 2005. Distribution géographique des cancers en Valais, 1989-2000. Registre des tumeurs. Observatoire Valaisan de la Santé 2005. Marques-Vidal P, Cerveira J, Paccaud F, Cornuz J, 2011. Smoking trends in Switzerland, 1992-2007: a time for optimism? J Epidemiol Comm Health 65, 281-286.

National Institute for Cancer Epidemiology and Registration (NICER), 2011a. Statistics of cancer mortality 1984-2008.

National Institute for Cancer Epidemiology and Registration (NICER), 2011b. Statistics of cancer incidence 1984-2008.

Oberaigner W, Vittadello F, 2010. Cancer mapping in alpine regions 2001-2005 (Austria, Italy, Slovenia, Switzerland). Innsbruck.

PAHO, 2002. Pan American Health Organization: celebrating 100 years of health, standardization: a classic epidemiological method for the comparison of rates. Epidemiol Bull 23, 3.

Peto R, Lopez AD, Boreham J, Thun M, Heath C, 1992. Mortality from tobacco in developed countries: indirect estimation from national vital statistics. Lancet 339, 1268-1270.

Samet J, Avila-Tang E, Boffetta P, Hannan L, Olivo-Marston S, Thun M, Rudin C, 2009. Lung cancer in never smokers: clinical epidemiology and environmental risk factors. Clin Cancer Res 15, 5626-5645.

Schopper D, Obrist R, 2005. Nationales Krebsprogramm für die Schweiz 2005-2010. Oncosuisse, Bern.

Schrader H, 1997. Entwicklungstendenzen ländlicher Räume in Deutschland und ihre Förderung durch die EUStrukturpolitik. In: Die ländlichen Räume in Deutschland und deren Besonderheit in Mecklenburg Vorpommern. Universität Rostock.

Schüler G, Bopp M, 1997. Atlas der Krebsmortalität in der 
Schweiz, 1970-1990. Birkhäuser Verlag.

Sitas F, Douglas AJ, Webster EC, 1989. Respiratory disease mortality patterns among South African iron moulders. Brit J Ind Med 46, 310-315.

Sturtz S, Ickstadt K, 2007. A descriptive and model-based spatial comparison of the standardised mortality ratio and the age-standardized mortality rate. Geospat Health 2, 255-266.

Subramanian J, Govindan R, 2007. Lung cancer in never smokers: a review. J Clin Oncol 25, 561-570.

Torok S, Hegedus B, Laszlo V, Hoda M, Ghanim B, Berger W,
Klepetko W, Dome B, Ostoros G, 2011. Lung cancer in never smokers. Future Oncol 7, 1195-1211.

Tyczynski JE, Bray F, Parkin DM, 2003. Lung cancer in Europe in 2000: epidemiology, prevention and early detection. Lancet Oncol 4, 45-55.

Xia H, Carlin B, Waller LA, 1997. Hierarchical models for mapping Ohio lung cancer rates. Environmetrics 8, 107-120.

Zeeb H, Schannoun F, 2009. WHO handbook on indoor radon: a public health perspective. Geneva: World Health Organization. 
Supplementary data
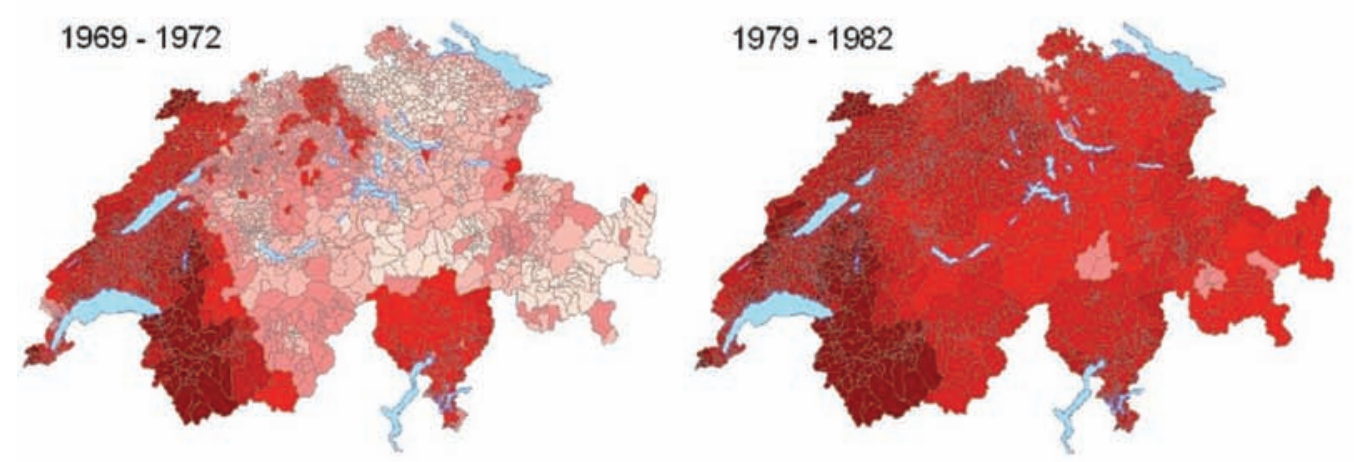

Age standardised mortality ratio
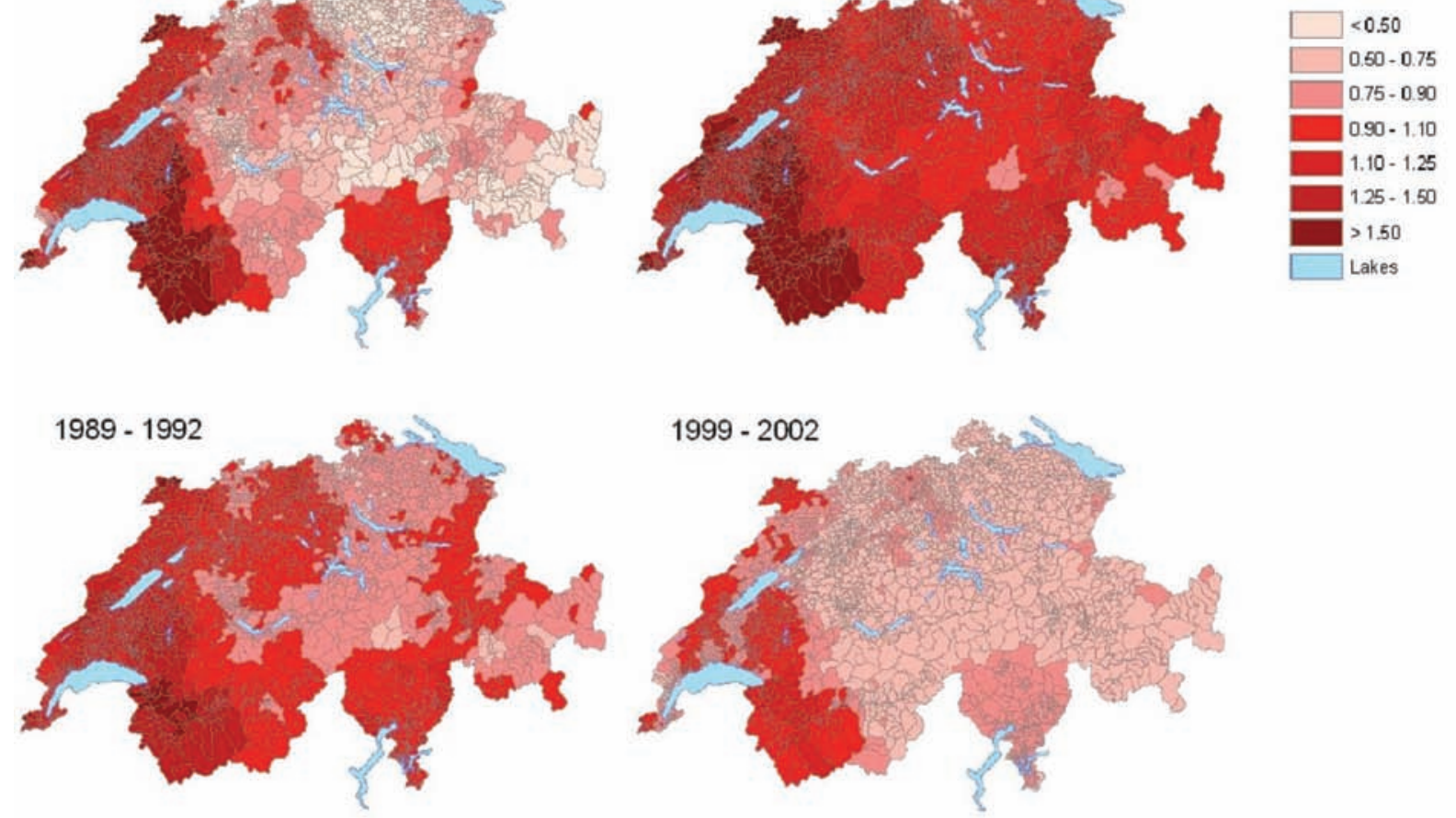

Fig. S1. Geographical distribution of tobacco-related cancer mortality risks from 1969-1972 to 1999-2002 in Switzerland for males aged 35-59 years.
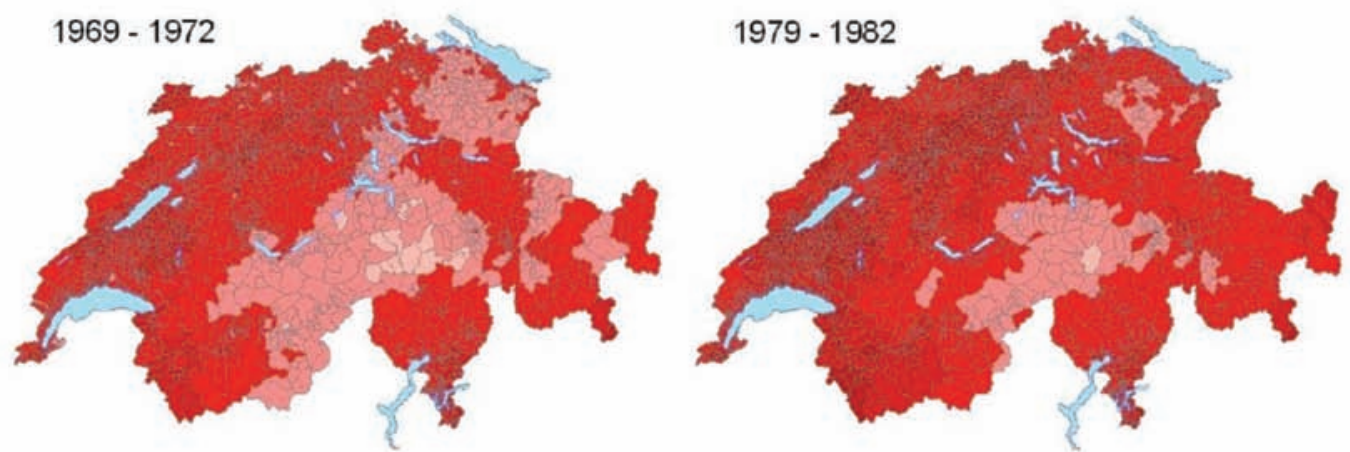

Age standardised

mortality ratio
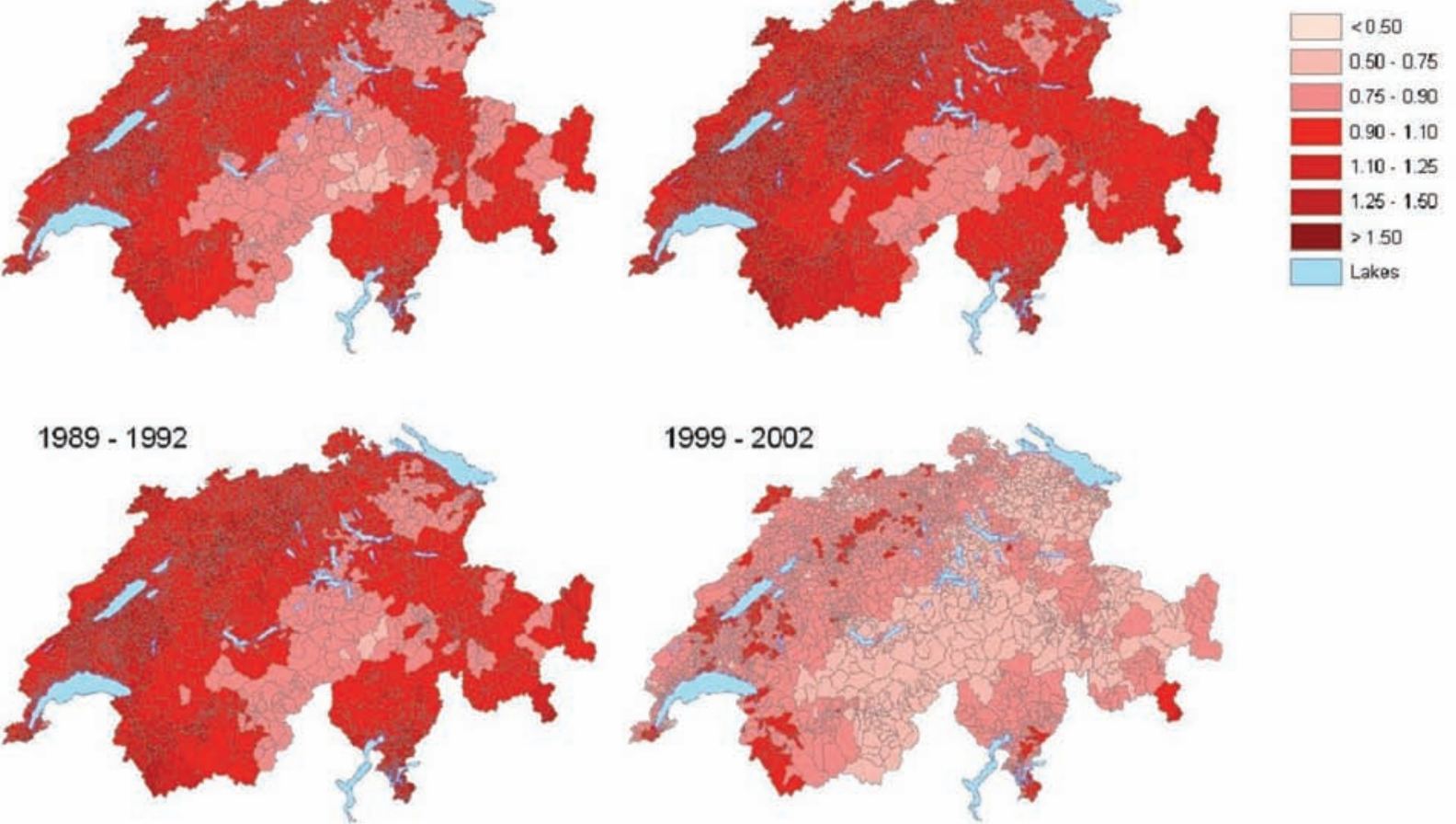

Fig. S2. Geographical distribution of tobacco-related cancer mortality risks from 1969-1972 to 1999-2002 in Switzerland for males aged 60 years and above. 

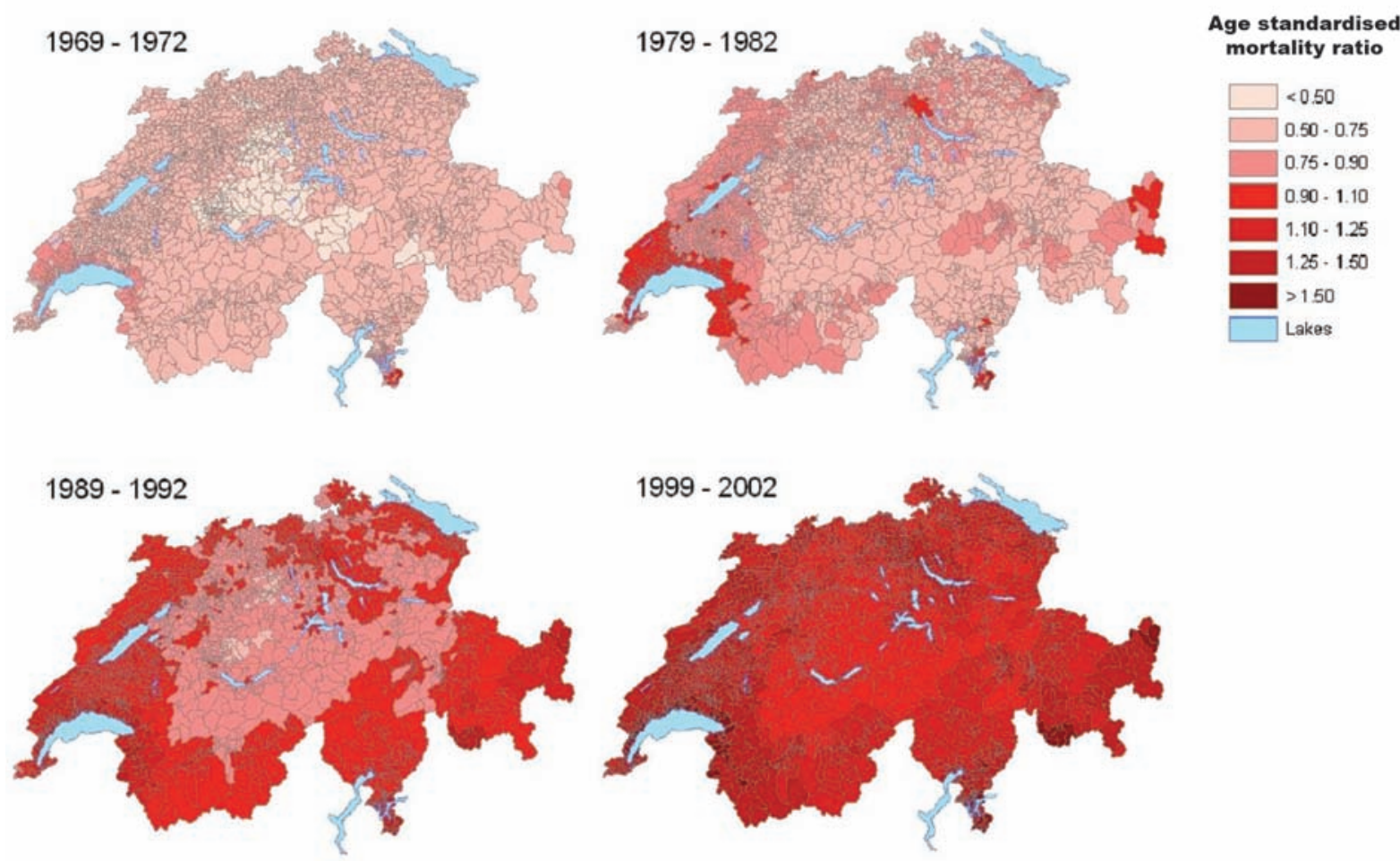

Fig. S3. Geographical distribution of tobacco-related cancer mortality risks from 1969-1972 to 1999-2002 in Switzerland for females aged 35-59 years.
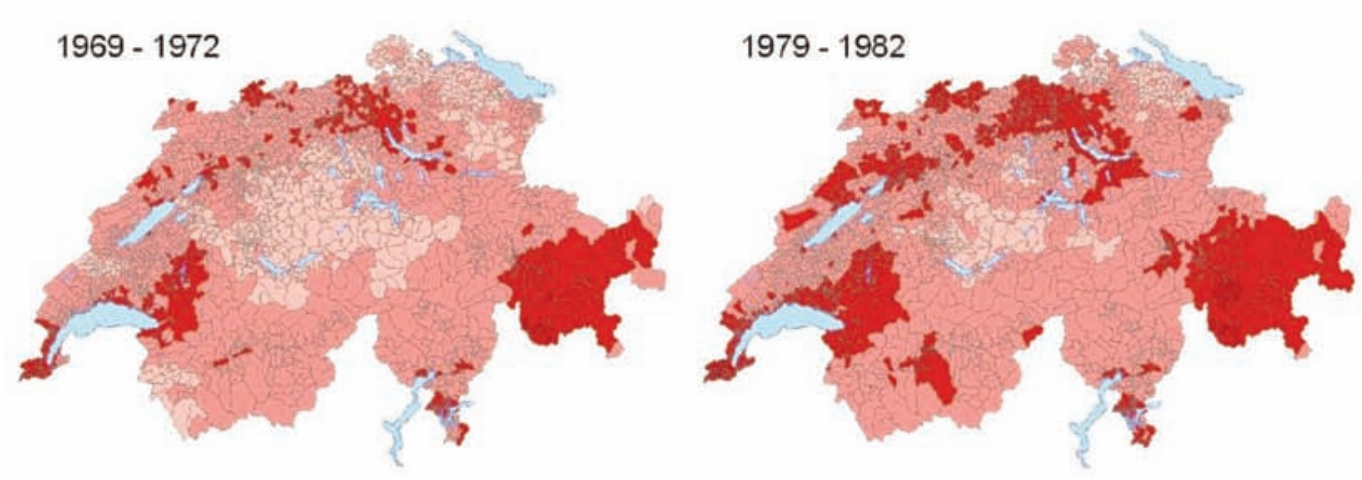

\section{Age standardised} mortality ratio
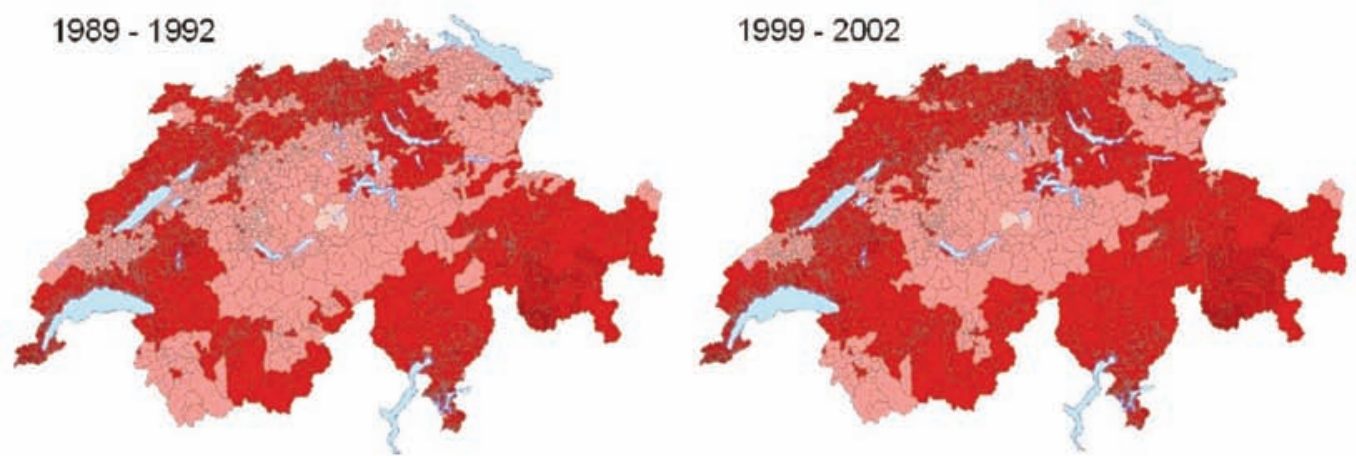

Fig. S4. Geographical distribution of tobacco-related cancer mortality risks from 1969-1972 to 1999-2002 in Switzerland for females aged 60 years and above. 
(a) Male, age $35-59$ years

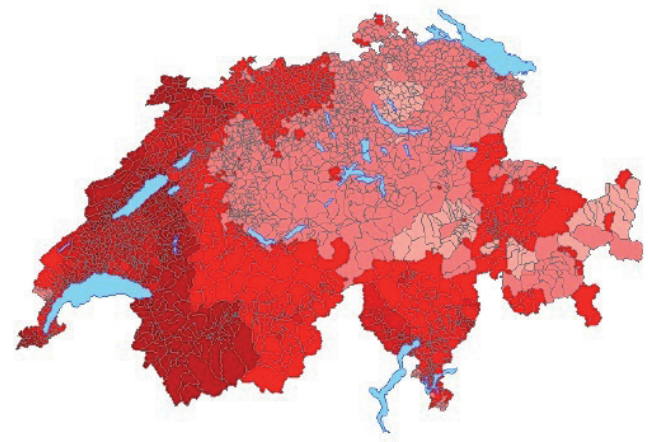

(c) Female, age 35-59 years

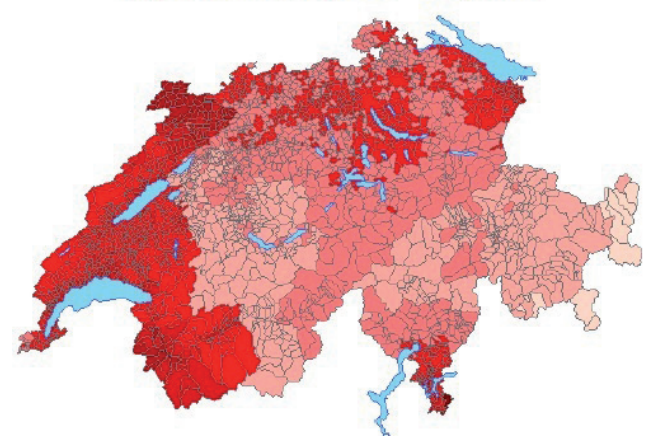

(b) Male, age $\geq 60$ years

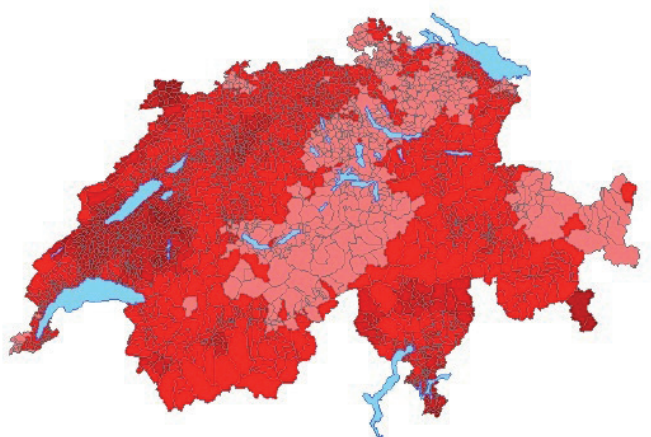

(d) Female, age $\geq 60$ years

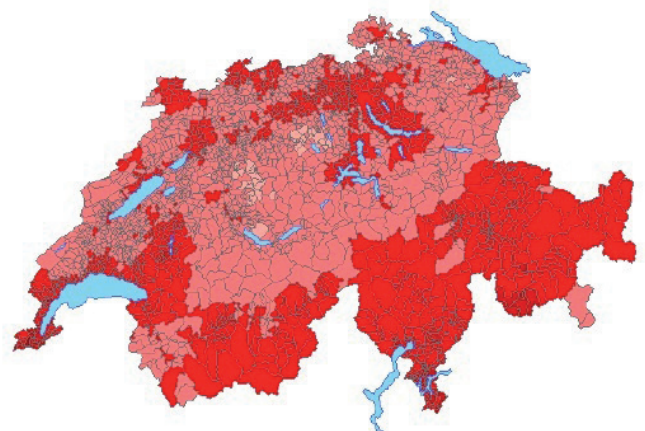

Fig. S5. Geographical distribution of age- and gender-specific tobacco-related cancer mortality risks in Switzerland in 1999-2002.

(a) Male, age 35-59 years

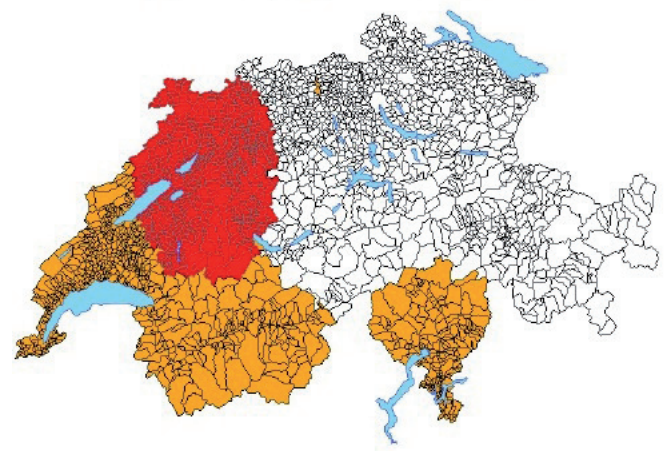

(c) Female, age 35-59 years

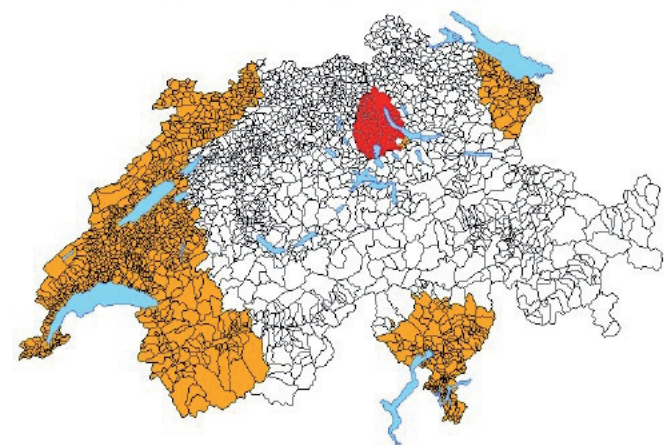

(b) Male, age $\geq 60$ years

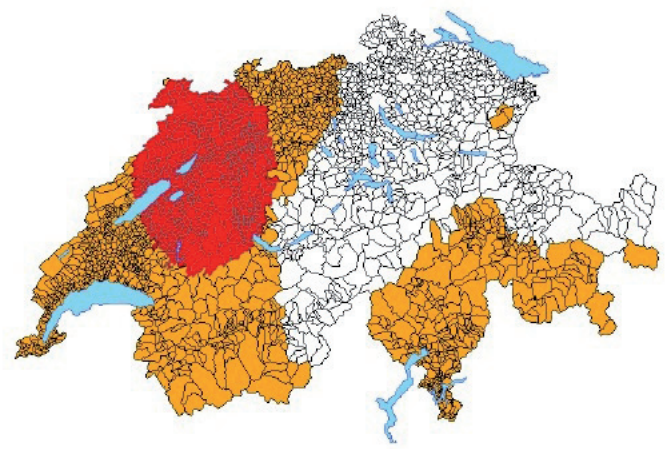

(d) Female, age $\geq 60$ years

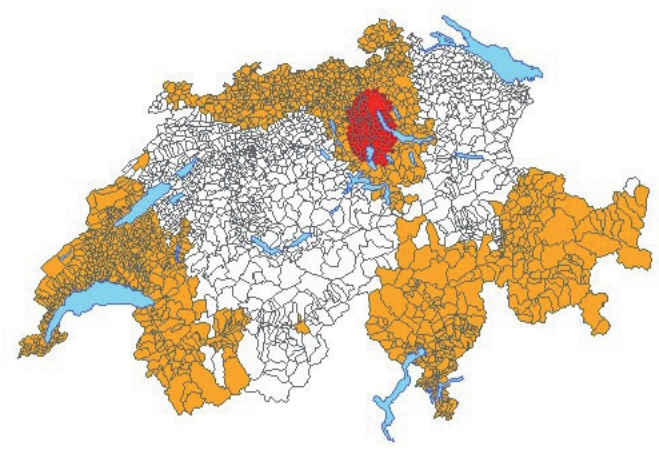

Fig. S6. Clusters of age- and gender-specific tobacco-related cancer mortality risks in Switzerland in the period 1999-2002* (*according to Kulldorff's statistic; red colour = highly significant clustering; yellow colour = significant clustering at a lower level). 
Table S1. Interpretation of the results of the spatial negative binomial regression analysis with interaction terms for age- and gender-specific lung cancer mortality in Switzerland.

\begin{tabular}{|c|c|c|c|c|}
\hline Factor 1 & Factor 2 & $1979-1982$ & $1989-1992$ & $1999-2002$ \\
\hline Dwelling & Language & & Male, age $35-59$ years & \\
\hline Urban & German & $1.04(0.80 ; 1.36)$ & $0.98(0.71 ; 1.32)$ & $0.60(0.45 ; 0.80)$ \\
\hline Urban & French & $1.26(0.80 ; 1.93)$ & $0.98(0.61 ; 1.59)$ & $0.78(0.49 ; 1.23)$ \\
\hline Urban & Italian & $0.90(0.48 ; 1.64)$ & $0.86(0.47 ; 1.62)$ & $0.48(0.42 ; 0.62)$ \\
\hline Urban & Romansh & $1.07(0.19 ; 5.73)$ & $1 *$ & $1.09(0.19 ; 5.59)$ \\
\hline Rural & German & $1.02(0.91 ; 1.15)$ & $0.75(0.65 ; 0.85)$ & $0.49(0.43 ; 0.56)$ \\
\hline Rural & French & $1.23(0.92 ; 1.63)$ & $0.98(0.71 ; 1.32)$ & $0.63(0.46 ; 0.85)$ \\
\hline Rural & Italian & $0.88(0.55 ; 1.38)$ & $0.86(0.55 ; 1.34)$ & $0.46(0.28 ; 0.75)$ \\
\hline Rural & Romansh & $1.04(0.22 ; 4.84)$ & $3.42(1.01 ; 13.07)$ & $0.89(0.18 ; 3.86)$ \\
\hline Dwelling & Language & & Male, age $\geq 60$ years & \\
\hline Urban & German & $1.13(0.96 ; 1.34)$ & $1.57(1.32 ; 1.89)$ & $0.79(0.66 ; 0.93)$ \\
\hline Urban & French & $1.32(1.00 ; 1.76)$ & $1.19(0.91 ; 1.58)$ & $0.92(0.70 ; 1.23)$ \\
\hline Urban & Italian & $1.45(0.99 ; 2.12)$ & $1.36(0.93 ; 2.01)$ & $0.99(0.97 ; 1.05)$ \\
\hline Urban & Romansh & $1.06(0.45 ; 2.57)$ & $1.48(0.67 ; 3.51)$ & $1.24(0.56 ; 2.99)$ \\
\hline Rural & German & $1.26(1.17 ; 1.35)$ & $1.35(1.26 ; 1.46)$ & $1.09(1.01 ; 1.18)$ \\
\hline Rural & French & $1.47(1.22 ; 1.77)$ & $1.57(1.31 ; 1.89)$ & $1.28(1.06 ; 1.55)$ \\
\hline Rural & Italian & $1.61(1.20 ; 2.14)$ & $1.80(1.36 ; 2.41)$ & $1.48(1.10 ; 1.97)$ \\
\hline Rural & Romansh & $1.19(0.55 ; 2.59)$ & $1.96(0.97 ; 4.21)$ & $1.73(0.86 ; 3.77)$ \\
\hline Dwelling & Language & & Female, age 35-59 years & \\
\hline Urban & German & $1.62(0.68 ; 3.83)$ & $2.81(1.17 ; 6.14)$ & $3.44(1.52 ; 7.10)$ \\
\hline Urban & French & $2.09(0.53 ; 8.03)$ & $2.59(0.70 ; 8.36)$ & $3.86(1.08 ; 11.91)$ \\
\hline Urban & Italian & $1.35(0.22 ; 8.15)$ & $3.47(0.73 ; 16.03)$ & $3.58(3.71 ; 6.06)$ \\
\hline Urban & Romansh & $1 *$ & $4.27(1.47 ; 24.19)$ & $1 *$ \\
\hline Rural & German & $1.40(0.89 ; 1.99)$ & $2.47(1.67 ; 3.39)$ & $3.55(2.37 ; 4.89)$ \\
\hline Rural & French & $1.81(0.69 ; 4.16)$ & $2.81(1.17 ; 6.14)$ & $3.98(1.69 ; 8.20)$ \\
\hline Rural & Italian & $1.17(0.28 ; 4.22)$ & $3.77(1.20 ; 11.78)$ & $2.68(0.87 ; 8.68)$ \\
\hline Rural & Romansh & $1 *$ & $1 *$ & $1 *$ \\
\hline Dwelling & Language & & Female, age $\geq 60$ years & \\
\hline Urban & German & $1.44(0.86 ; 2.39)$ & $1.71(1.05 ; 2.70)$ & $2.54(1.66 ; 3.80)$ \\
\hline Urban & French & $1.66(0.75 ; 3.64)$ & $2.51(1.19 ; 5.07)$ & $3.08(1.58 ; 5.96)$ \\
\hline Urban & Italian & $1.81(0.62 ; 5.17)$ & $2.47(0.92 ; 6.32)$ & $2.22(1.69 ; 3.48)$ \\
\hline Urban & Romansh & $1 *$ & $1 *$ & $1 *$ \\
\hline Rural & German & $0.95(0.73 ; 1.18)$ & $1.25(0.98 ; 1.53)$ & $2.08(1.68 ; 2.50)$ \\
\hline Rural & French & $1.09(0.63 ; 1.80)$ & $1.71(1.05 ; 2.70)$ & $2.52(1.60 ; 3.92)$ \\
\hline Rural & Italian & $1.19(0.52 ; 2.56)$ & $1.67(0.82 ; 3.37)$ & $2.87(1.47 ; 5.51)$ \\
\hline Rural & Romansh & $1 *$ & /* & $1 *$ \\
\hline
\end{tabular}

"Due to very small counts, the estimates are not meaningful. 
Table S2. Interpretation of the results of the spatial negative binomial regression analysis with interaction terms for age- and gender-specific tobacco-related cancer mortality in Switzerland.

\begin{tabular}{|c|c|c|c|c|}
\hline Factor 1 & Factor 2 & 1979-1982 & 1989-1992 & 1999-2002 \\
\hline Dwelling & Language & & Male, age 35-59 years & \\
\hline Urban & German & $0.98(0.79 ; 1.24)$ & $1.05(0.83 ; 1.36)$ & $0.63(0.49 ; 0.80)$ \\
\hline Urban & French & $1.16(0.81 ; 1.68)$ & $0.98(0.68 ; 1.42)$ & $0.77(0.52 ; 1.12)$ \\
\hline Urban & Italian & $1.01(0.61 ; 1.63)$ & $0.93(0.58 ; 1.51)$ & $0.63(0.57 ; 0.73)$ \\
\hline Urban & Romansh & $1.01(0.27 ; 3.62)$ & $2.14(0.77 ; 6.99)$ & $0.85(0.23 ; 3.27)$ \\
\hline Rural & German & $1.08(0.97 ; 1.19)$ & $0.87(0.79 ; 0.98)$ & $0.63(0.56 ; 0.70)$ \\
\hline Rural & French & $1.27(1.01 ; 1.62)$ & $1.05(0.83 ; 1.36)$ & $0.78(0.60 ; 0.98)$ \\
\hline Rural & Italian & $1.10(0.75 ; 1.57)$ & $1.00(0.71 ; 1.45)$ & $0.68(0.47 ; 0.99)$ \\
\hline Rural & Romansh & $1.10(0.34 ; 3.48)$ & $2.31(0.95 ; 6.69)$ & $0.85(0.26 ; 2.87)$ \\
\hline Dwelling & Language & & Male, age $\geq 60$ years & \\
\hline Urban & German & $1.03(0.91 ; 1.17)$ & $1.22(1.07 ; 1.40)$ & $0.71(0.63 ; 0.80)$ \\
\hline Urban & French & $1.11(0.90 ; 1.37)$ & $1.02(0.83 ; 1.25)$ & $0.79(0.64 ; 0.97)$ \\
\hline Urban & Italian & $1.08(0.82 ; 1.43)$ & $1.04(0.77 ; 1.35)$ & $0.83(0.80 ; 0.87)$ \\
\hline Urban & Romansh & $1.37(0.74 ; 2.51)$ & $1.40(0.76 ; 2.57)$ & $1.22(0.68 ; 2.21)$ \\
\hline Rural & German & $1.11(1.05 ; 1.17)$ & $1.11(1.06 ; 1.18)$ & $0.85(0.80 ; 0.90)$ \\
\hline Rural & French & $1.20(1.05 ; 1.37)$ & $1.22(1.07 ; 1.40)$ & $0.94(0.82 ; 1.08)$ \\
\hline Rural & Italian & $1.16(0.95 ; 1.44)$ & $1.21(0.99 ; 1.51)$ & $0.98(0.80 ; 1.20)$ \\
\hline Rural & Romansh & $1.48(0.86 ; 2.52)$ & $1.67(0.98 ; 2.87)$ & $1.46(0.87 ; 2.46)$ \\
\hline Dwelling & Language & & Female, age $35-59$ years & \\
\hline Urban & German & $1.19(0.68 ; 2.08)$ & $1.82(1.05 ; 3.18)$ & $1.84(1.12 ; 3.02)$ \\
\hline Urban & French & $1.65(0.69 ; 3.93)$ & $1.84(0.79 ; 4.32)$ & $2.37(1.07 ; 5.11)$ \\
\hline Urban & Italian & $1.15(0.38 ; 3.67)$ & $2.06(0.69 ; 6.25)$ & $1.88(1.71 ; 2.74)$ \\
\hline Urban & Romansh & $1 *$ & $1 *$ & $1 *$ \\
\hline Rural & German & $1.15(0.89 ; 1.51)$ & $1.45(1.13 ; 1.87)$ & $1.88(1.50 ; 2.36)$ \\
\hline Rural & French & $1.59(0.90 ; 2.85)$ & $1.82(1.05 ; 3.18)$ & $2.42(1.44 ; 3.99)$ \\
\hline Rural & Italian & $1.12(0.50 ; 2.66)$ & $2.05(0.92 ; 4.60)$ & $1.54(0.97 ; 4.35)$ \\
\hline Rural & Romansh & $1 *$ & $1 *$ & $1 *$ \\
\hline Dwelling & Language & & Female age $\geq 60$ years & \\
\hline Urban & German & $1.09(0.87 ; 1.35)$ & $1.15(0.90 ; 1.47)$ & $1.16(0.95 ; 1.41)$ \\
\hline Urban & French & $1.10(0.76 ; 1.58)$ & $1.32(0.92 ; 1.90)$ & $1.25(0.89 ; 1.75)$ \\
\hline Urban & Italian & $1.03(0.64 ; 1.68)$ & $1.35(0.86 ; 2.09)$ & $1.08(0.98 ; 1.26)$ \\
\hline Urban & Romansh & $1.67(0.62 ; 4.66)$ & $0.96(0.33 ; 2.77)$ & $1.38(0.55 ; 3.47)$ \\
\hline Rural & German & $1.03(0.94 ; 1.15)$ & $0.99(0.89 ; 1.09)$ & $1.07(0.97 ; 1.17)$ \\
\hline Rural & French & $1.04(0.82 ; 1.35)$ & $1.15(0.90 ; 1.47)$ & $1.16(0.91 ; 1.45)$ \\
\hline Rural & Italian & $0.98(0.69 ; 1.43)$ & $1.18(0.84 ; 1.62)$ & $1.26(0.91 ; 1.76)$ \\
\hline Rural & Romansh & $1.58(0.67 ; 3.97)$ & $0.84(0.33 ; 2.13)$ & $1.27(0.57 ; 2.87)$ \\
\hline
\end{tabular}

*Due to very small counts, the estimates are not meaningful. 